\title{
DIVERSIDAD FITOECOLÓGICA, BIOTÍPICA Y DE PROCEDENCIA EN MIRALRÍO. COMPARACIÓN CON LA FLORA DE LAALCARRIA OCCIDENTAL DE GUADALAJARA
}

\author{
Juan Javier García-Abad Alonso \\ Departamento de Geología, Geografía y Medio Ambiente. Universidad de Alcalá \\ juanj.garciaabad@uah.es \\ Josep Maria Panareda Clopés \\ Departamento de Geografía Física y Análisis Geográfico Regional. Universidad de Barcelona \\ jmpanareda@gmail.com
}

\section{RESUMEN}

A partir de inventarios de plantas vasculares, se establecen los espectros fitoecológico, biotípico y de procedencia en nueve cuadrículas U.T.M. (ED50) de $1 \times 1 \mathrm{~km}$ contiguas y en su agregado de $3 \times 3 \mathrm{~km}$, en torno a Miralrío (Guadalajara). Se completa así, como segunda parte, el análisis de fitodiversidad geográfica iniciado anteriormente (García-Abad y Panareda, 2012). Los resultados obtenidos se relacionan con los correspondientes de la flora de La Alcarria Occidental de Guadalajara a la que pertenece. La compartimentación geográfica de los inventarios y conjuntos florísticos permite una comparación anidada en tres niveles.

Palabras clave: Espectro biotípico, Espectro fitoecológico, Espectro de procedencia, Fitodiversidad geográfica, La Alcarria Occidental de Guadalajara, Miralrío.

Fecha de recepción: diciembre 2012.

Fecha de aceptación: octubre 2013. 


\section{ABSTRACT}

It carries out a vascular plant inventory in order to establish ecological, life-forms and provenance spectra in nine contiguous $1 \times 1-\mathrm{km}$ grid cells (Datum ED50), and their $3 \times 3-\mathrm{km}$ aggregate cell around to little town of Miralrio (Province of Guadalajara, Central Spain). This paper continues, as the second part, the geographical diversity study conducted by García-Abad and Panareda (2012). Futhermore, we aim: 1) to present those spectra for the sub-region to which Miralrío belongs; 2) to compare all these spectra and to get phytogeographical interpretations; and finally 3 ) to realize a geographically nested analysis of all outcomes.

Key words: Ecological spectrum, Life forms spectrum, Chorological spectrum, Geographical Phytodiversity, The Western «La Alcarria» of the Guadalajara province (Central Spain), Miralrío.

\section{INTRODUCCIÓN, MÉTODO Y OBJETIVOS}

Este trabajo continúa el estudio sobre fitodiversidad efectuado en Miralrío (Guadalajara) por García-Abad y Panareda (2012). En él ya fueron expuestos ampliamente los rasgos geográficos del área de estudio y el método empleado. Éste consistió en inventariar entre abril y julio de 2007 plantas en nueve cuadrículas U.T.M. (ED50) de $1 \times 1 \mathrm{~km}$ por separado que, siendo contiguas, formaban a su vez otra cuadrícula de $3 \times 3 \mathrm{~km}(9 \mathrm{C}$, a partir de ahora). Se determinaron los espectros taxonómicos de todas esas unidades. Se pudieron comparar no sólo los resultados de las unidades de $1 \mathrm{~km}^{2}$ entre sí, sino también anidadamente los de cada una de ellas con el conjunto de $9 \mathrm{~km}^{2}$. Se incorporó un tercer nivel de anidamiento, al comparar los anteriores resultados con los de la flora de la subregión de La Alcarria Occidental de Guadalajara a la que pertenecen (AOG, a partir de ahora).

Las Figuras 1 y 2 muestran el área de estudio. Su localización dentro de AOG (3.200 $\left.\mathrm{km}^{2}\right)$ y de la región natural de La Alcarria Occidental y Mesa de Ocaña $\left(6.700 \mathrm{~km}^{2}\right)$ a la que pertenece puede observarse en García-Abad y Panareda (2012, p. 248). Sobre esta región se efectuaron trabajos previos (García-Abad, 2009 y 2011) aplicando un método de análisis florístico que, con algunas variantes, se emplea en el presente trabajo.

Los objetivos ahora son: a) presentar los espectros fitoecológico, biotípico y de procedencia de AOG; b) presentar los mismos espectros en esas nueve cuadrículas de $1 \times 1 \mathrm{~km}$, por separado y en su conjunto 9C; c) comparar los espectros obtenidos e interpretarlos fitogeográfica y geoecológicamente; y d) efectuar un análisis comparado y anidado de esos resultados. 
Figura 1

MAPA DE LA CUADRÍCULA U.T.M. 30TWL0425 DE 3×3 KM DE LADO (ED50) PROSPECTADA FLORÍSTICAMENTE (MIRALRIO). ATIÉNDASE A LA IDENTIFICACIÓN DE CADA UNA DE LAS CUADRÍCULAS DE 1×1 KM

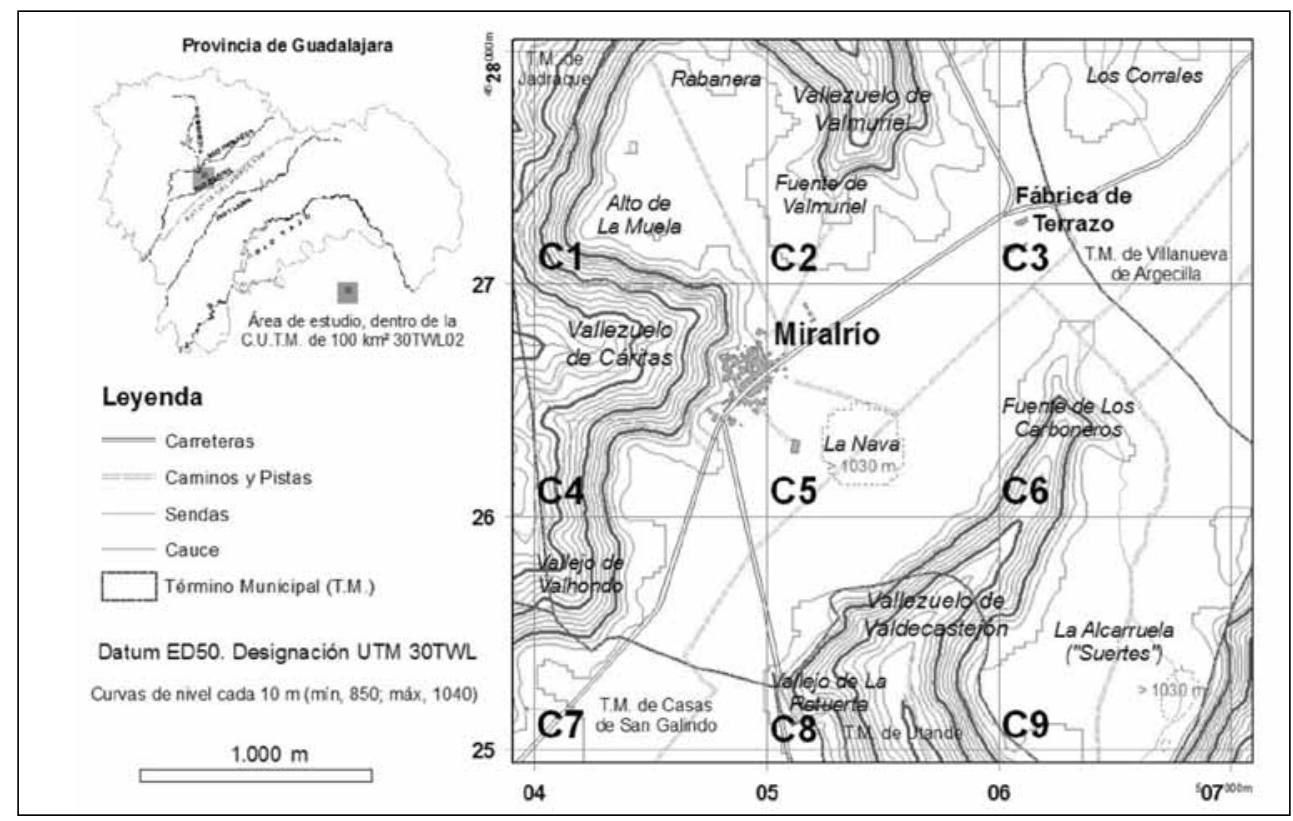

Fuente: García-Abad y Panareda (2012), modificado.

Figura 2

ORTOFOTOGRAFÍA DE AGOSTO DE 2002 DEL ÁREA PROSPECTADA

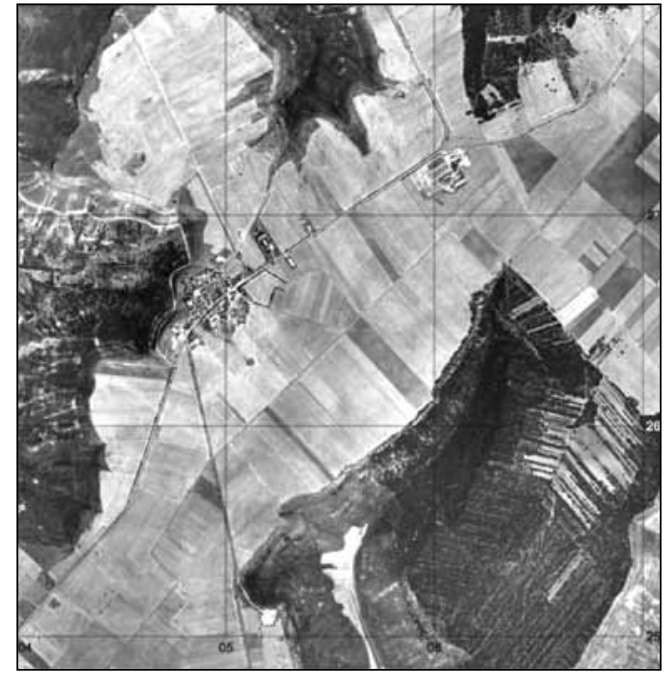

Fuente: SIGPAC (Ministerio de Agricultura, Pesca y Alimentación), http://sigpac.mapa.es/fega/visor. 


\section{RESULTADOS}

\section{II.1. Espectro fitoecológico de la flora autóctona de AOG y de Miralrío}

En base a la adscripción de plantas a clases fitosociológicas según Rivas-Martínez et al. (2002) y a planteamientos relacionados con la misma (García-Abad, 2011), se tipifica fitoecológicamente la flora autóctona de la subregión de AOG, la del conjunto de las nueves cuadrículas (9C) y la de cada una de las cuadrículas por separado (Tabla 1).

Tabla 1

NÚMERO DE PLANTAS AUTÓCTONAS ${ }^{1}$ SEGÚN SU APETENCIA ECOLÓGICA MÁS CARACTERÍSTICA²

\begin{tabular}{|c|c|c|c|c|c|c|c|c|c|c|c|c|c|}
\hline $\begin{array}{l}\text { GRANDES GRUPOS } \\
\text { FITOECOLÓGICOS }\end{array}$ & $\mathbf{A O G}^{3}$ & $9 C^{4}$ & $\mathrm{C} 4$ & C8 & $\mathrm{C} 2$ & C6 & C7 & C9 & C1 & $\mathrm{C} 3$ & C5 & FC $^{5}$ & $\%$ \\
\hline $\begin{array}{l}\text { Hrv. Herbazales ruderales } \\
\text { y arvenses }\end{array}$ & 278 & 182 & 140 & 125 & 127 & 106 & 116 & 80 & 114 & 118 & 126 & 47 & 25,7 \\
\hline $\begin{array}{l}\text { av. Ecologia amplia, } \\
\text { variada o no determinada }\end{array}$ & 175 & 77 & 47 & 48 & 44 & 44 & 37 & 48 & 32 & 35 & 27 & 10 & 12,8 \\
\hline $\begin{array}{l}\text { Ht. Herbazales terofiticos no } \\
\text { nitrófilos }\end{array}$ & 122 & 71 & 48 & 46 & 43 & 43 & 44 & 52 & 42 & 45 & 32 & 19 & 26,8 \\
\hline $\begin{array}{l}\text { Hm. Herbazal-matorrales } \\
\text { mesófilos a un poco xéricos }\end{array}$ & 113 & 59 & 47 & 44 & 43 & 43 & 41 & 42 & 40 & 40 & 24 & 12 & 20,3 \\
\hline $\begin{array}{l}\text { Pmh. Praderas meso- } \\
\text { higrófilas antropozoógenas }\end{array}$ & 101 & 47 & 37 & 22 & 30 & 20 & 19 & 10 & 12 & 9 & 12 & 2 & 4,3 \\
\hline Ms. Matorrales seriales & 99 & 48 & 38 & 44 & 40 & 42 & 38 & 42 & 35 & 33 & 22 & 18 & 37,5 \\
\hline $\begin{array}{l}\text { Snn. Veg. subnemoral } \\
\text { nitrófila a muy poco nitrófila }\end{array}$ & 75 & 48 & 33 & 23 & 27 & 23 & 15 & 21 & 13 & 10 & 13 & 3 & 6,4 \\
\hline $\begin{array}{l}\text { Dul. Veg. dulceacuicola } \\
\text { fontanal, anfibia y turfófila }\end{array}$ & 54 & 13 & 7 & 2 & 4 & 2 & & 2 & 1 & & & & \\
\hline $\begin{array}{l}\text { Bpe. Bosques perennifolios } \\
\text { y/o esclerófilos }\end{array}$ & 38 & 25 & 15 & 17 & 12 & 17 & 13 & 15 & 13 & 10 & 14 & 6 & 24,0 \\
\hline $\begin{array}{l}\text { Rup. Veg. rupicola y/o de } \\
\text { ámbitos muy pedregosos }\end{array}$ & 37 & 20 & 10 & 15 & 13 & 7 & 11 & 11 & 13 & 7 & 6 & & \\
\hline $\begin{array}{l}\text { Asp. Arbustedas seriales } \\
\text { preforestales }\end{array}$ & 34 & 21 & 17 & 12 & 13 & 18 & 15 & 13 & 12 & 7 & 10 & 5 & 23,8 \\
\hline $\begin{array}{l}\text { Hbx. Herbazal-matorrales } \\
\text { basófilos abiertos y/o xéricos }\end{array}$ & 32 & 19 & 14 & 17 & 14 & 15 & 12 & 14 & 11 & 13 & 11 & 8 & 42,1 \\
\hline $\begin{array}{l}\text { BAe. Bosques y Arbustedas } \\
\text { edafohigrófilos }\end{array}$ & 30 & 9 & 8 & 3 & 3 & 3 & 1 & 2 & & 1 & 4 & & \\
\hline $\begin{array}{l}\text { Bmc. Bosques mesófilos } \\
\text { caducifolios o marcescentes }\end{array}$ & 24 & 14 & 8 & 9 & 3 & 11 & 6 & 12 & 1 & 5 & 4 & 1 & 7,1 \\
\hline Msn. Matorrales subnitrófilos & 22 & 13 & 11 & 9 & 9 & 9 & 10 & 7 & 13 & 6 & 7 & 3 & 23,1 \\
\hline Hal Vegetación halófila & 16 & 1 & & 1 & & & & & & & & & \\
\hline Acu. Vegetación acuática & 11 & & & & & & & & & & & & \\
\hline $\begin{array}{l}\text { Oro. Herbazal-matorrales } \\
\text { oro-criófilos }\end{array}$ & 9 & 3 & & 2 & 2 & 1 & 1 & 3 & 1 & 2 & & & \\
\hline$N^{\circ}$ de Grandes Grupos & 18 & 17 & 15 & 17 & 16 & 16 & 15 & 16 & 15 & 15 & 14 & - & - \\
\hline $\mathrm{N}^{\circ}$ Plantas (Riqueza) & 1270 & 669 & 480 & 439 & 427 & 404 & 379 & 374 & 353 & 341 & 312 & 134 & $\mathbf{2 0 , 0}$ \\
\hline
\end{tabular}

1 Táxones hasta el nivel de variedad. ${ }^{2}$ Para no atomizar en exceso el análisis, en este trabajo se agrupan $a d$ hoc en 18 grandes grupos (se indican los códigos numéricos empleados por Rivas-Martínez et al., 2002): Acu, plantas características de los sintáxones de las clases 2 y 3; Asp, 65 y 66; av, plantas sin adscripción; BAe, 70 y 71 ; Bmc, 76; Bpe, 74, 75 y 77; Dul, 8, 9, 11, 12 y 14; Hal, 16, 17, 19, 20, 22, 23 y 25; Hbx, 55 y 56; Hm, 51 a 54 y 57 ; Hrv, 34, 35, 38 y 39; Ht, 50; Ms, 61, 62 y 64; Msn, 37; y Oro, 4; Pmh, 59; Rup, 26 a 29, 32 y 33; y Snn, 40, 41 y 43. ${ }^{3}$ AOG, La Alcarria Occidental de Guadalajara. ${ }^{4}$ 9C $=\mathrm{C} 1+\mathrm{C} 2+\mathrm{C} 3+\mathrm{C} 4+\mathrm{C} 5+\mathrm{C} 6+\mathrm{C} 7+\mathrm{C} 8+\mathrm{C} 9 .{ }^{\mathbf{5}}$ FC, Flora Común o número de plantas que estaban presentes en las nueve cuadrículas y porcentaje respecto a las inventariadas en $9 \mathrm{C}$. En el extremo inferior de estas columnas se indican en negrita los valores totales. NOTAS: A) Los grandes grupos aparecen, de arriba a abajo, ordenados de mayor a menor número de plantas implicadas en AOG. B) Las cuadrículas de $1 \times 1 \mathrm{~km}$ aparecen, de izquierda a derecha, ordenadas de mayor a menor riqueza florística.

Fuentes: AOG (extractadas de García-Abad, 2009), resto (Datos y elaboración propios) 
Los datos absolutos de esta Tabla se reducen a porcentajes en las Figuras 3 y 4 . Se pueden, así, comparar todas estas cifras teniendo en cuenta el anidamiento espacial de las unidades estudiadas.

Figura 3

ESPECTRO FITOECOLÓGICO DE LAS PLANTAS DE LAALCARRIA OCCIDENTAL DE GUADALAJARA

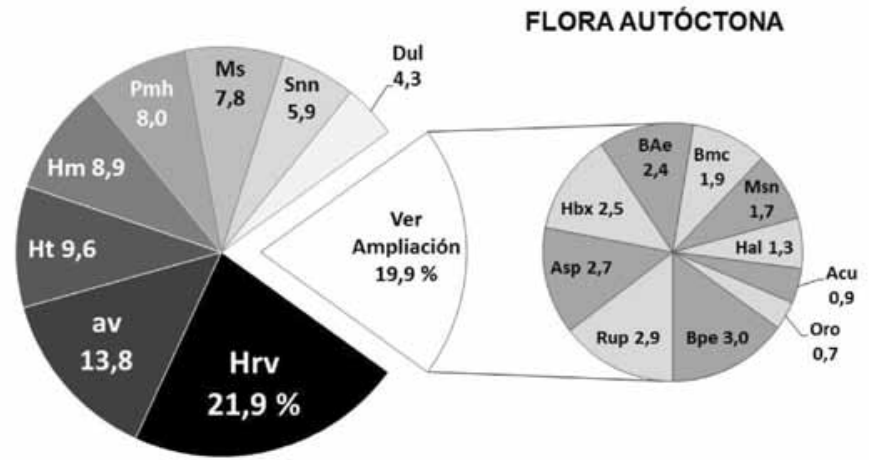

Abreviaturas: Véanse en Tabla 1

Fuente: García-Abad (2009, datos extractados para AOG). Elaboración propia.

Figura 4

ESPECTROS COMPARADOS DE LOS PRINCIPALES GRUPOS FITOECOLÓGICOS DE LAS NUEVE CUADRÍCULAS DE $1 \times 1$ KM Y DEL CONJUNTO FLORAL 9C DE 3×3 KM (COLUMNA NEGRA)

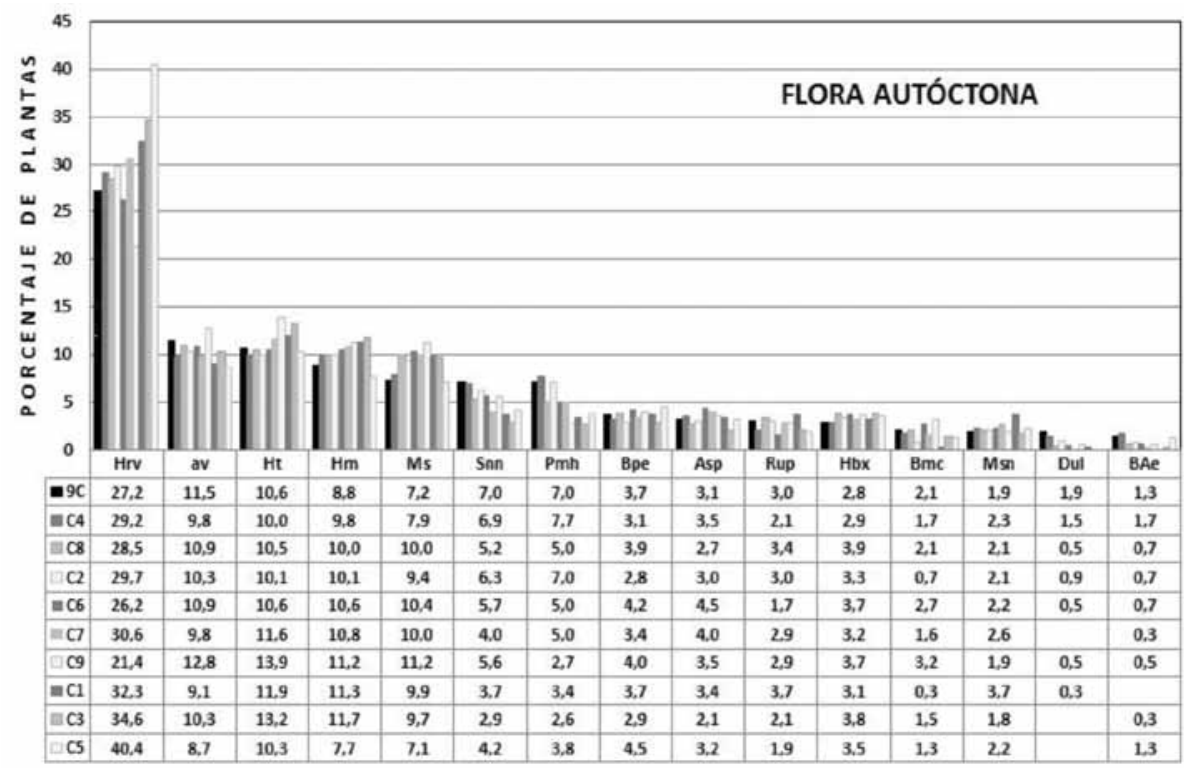

Abreviaturas: Véanse en Tabla 1. NOTAS: A) Los grupos fitoecológicos aparecen, de izquierda a derecha, ordenados de mayor a menor porcentaje en 9C. B) Las cuadrículas de $1 \times 1 \mathrm{~km}$ aparecen, de arriba a abajo, ordenadas de mayor a menor riqueza florística.

Fuente: Datos y elaboración propios. 
El espectro fitoecológico de la subregión de AOG es bastante similar al de la región de La Alcarria Occidental y Mesa de Ocaña a la que pertenece. Los rasgos comentados para esta región (García-Abad, 2011) se cumplen en general también en la subregión. De ellos, tan sólo merece reiterarse el claro liderazgo que tambien tienen las plantas ruderal-arvenses («Hrv») en AOG, pues componen más de una quinta parte del contingente florístico total (278 plantas de las 1270 totales).

En síntesis, en poco más de las tres cuartas partes de la flora, el orden fitoecológico actual de AOG muestra el siguiente modelo (Tabla 1 y Figura 3):

$$
\mathrm{Hrv}>\mathrm{av}>\mathrm{Ht}>\mathrm{Hm}>\mathrm{Pmh} \approx \mathrm{Ms}>\mathrm{Snn}
$$

En estos siete primeros términos, el orden del modelo fitoecológico de 9C se parece bastante al subregional (compárense los porcentajes de la Figura 4 con los de la Figura 3), con la excepción de que los tres últimos términos están prácticamente equiparados, por un descenso de «Pmh» de similar valor al aumento de «Snn». Aunque las cifras de esta variación no son especialmente grandes y, en todo caso, implican un grado similar de antropización general en Miralrío, sí indica que en este municipio las alteraciones por actividades forestales han sido algo mayores que las debidas a actividades ganaderas respecto al promedio subregional. Esto se comprueba, además, en los espectros particulares de las cuadrículas de $1 \times 1 \mathrm{~km}$ (pueden deducirse de la Figura 4), en los que «Pmh» ocupa casi siempre posiciones más retrasadas. En ellos se observa además que, cuanto menor es la riqueza, las plantas pioneras y recomponedoras de «Ht» $\mathrm{y}$ «Hm» adelantan posiciones en sus modelos correspondientes, haciendo retroceder a las menos especializadas del grupo «av». Esta modificación del modelo se produce como una tendencia general conforme disminuye la extensión de las unidades de anidamiento.

Al igual que en La Alcarria Occidental y Mesa de Ocaña (García-Abad, 2011), son 18 los grandes grupos fitoecológicos presentes en AOG. Con excepción de «Acu», pues no hay cauces suficientemente caudalosos para albergar este tipo de plantas, $\mathrm{y}$ «Hal» ${ }^{1}$, todos esos grandes grupos se encuentran en 9C. La diferencia fundamental de 9C respecto a la subregión de AOG es la mayor artificialización conjunta, pues la proporción de plantas ruderal-arvenses («Hrv») es superior en algo más de un 5\%. En el resto, las diferencias no son especialmente grandes ni indicativas, salvo en algunos matices, de modo que en un balance general debe admitirse una pauta fitoecológica relativamente análoga de 9C respecto al ámbito subregional AOG que lo contiene.

En el poco espacio $\left(9 \mathrm{~km}^{2}\right)$ del segundo nivel de anidamiento (9C), ya se encuentran casi dos tercios de todas las plantas ruderal-arvenses presentes en el amplio espacio del primer nivel (AOG). Ello muestra tanto la destacada contribución de este grupo fitoecológico «Hrv» a homogeneizar florísticamente el territorio, como la gran concentración espacial que alcanza ya en áreas de aquel tamaño (182 de las 278 plantas presentes en la subregión). Obviamente, las actividades humanas explican este rasgo espacio-funcional. En el tercer nivel de anidamiento (cuadrículas de $1 \mathrm{~km}^{2}$ por separado), este «fito-rasgo»

1 Se puede considerar que los ambientes propios de «Hal» tampoco están presentes, pues Agrostis nebulosa fue hallada en vertedero y su carácter en 9C es claramente adventicio. 
antrópico se acrecienta proporcionalmente, pues se hace palpable la muy fuerte concentración de esas plantas en áreas aún más reducidas: sólo en C4 se encuentran 140 plantas de «Hrv», es decir, la mitad de todas las presentes en los $3.200 \mathrm{~km}^{2}$ de AOG. En el extremo opuesto, C9 es la cuadrícula con menor artificialización, lo que pese a reducirse bastante ese contingente fitoecológico no evita que aún medren allí 80 plantas ruderal-arvenses, es decir, más de una cuarta parte de todas las del espacio continente superior (AOG) y casi el $44 \%$ de las del espacio anidado intermedio (9C). Aquella alta concentración territorial en áreas de $9 \mathrm{~km}^{2}$ la detentan también plantas propias de los bosques perennifolios («Bpe»), sus orlas preforestales («Asp») y cortejos herbáceos («Snn»), que agrupadamente también contribuyen a homogeneizar bastante el territorio (94 plantas de las 147 habidas en toda la subregión). Todavía destacan, por su importante número de plantas, los terófitos pioneros de ambientes medianamente a poco o nada alterados ( $« \mathrm{Ht} »)$ en contribuir, con cierto potencial, a homogeneizar florísticamente los paisajes alcarreños. En este caso, 71 de las 122 presentes en AOG ya se encuentran en 9C (el 58,2\%), oscilando en un rango de 48 a 32 plantas (43-26\%) una presencia nada desdeñable en los recintos de $1 \mathrm{~km}^{2}$. Pero es que además, en ese recinto de $3 \times 3 \mathrm{~km}$, son también bastantes los grandes grupos fitoecológicos que se acercan o superan un poco el $50 \%$ de presencia del total subregional.

Si se atiende al espectro particular de cada recinto por separado, el menor tamaño de las cuadrículas de $1 \times 1 \mathrm{~km}$ explica que en ellas estén ausentes algunos grupos fitoecológicos. Pese a ello, el promedio de grupos presentes es bastante elevado $(15,4$; con un rango absoluto de 17-14), lo que muestra cómo en ese reducido espacio se encuentran ya buena parte de los ambientes ecológicos propios del paisaje alcarreño. En estas cuadrículas, no hay vegetación acuática («Acu»), y «BAe», «Dul», «Oro»y «Hal» tienen una presencia de minoritaria a nula. Según sus proporciones internas, el liderazgo es siempre de las ruderales y arvenses (Tabla 1, Figura 4), pero es desigual en función del grado de antropización de cada cuadrícula $^{2}$. Con excepción de $\mathrm{C} 9$, los porcentajes alcanzados en el resto de cuadrículas (rango de $41-26 \%)$ son bastante mayores a los de AOG $(21,9 \%)$ y en diferente grado, dependiendo de la mayor o menor importancia relativa de bosques, matorrales y áreas humanizadas (cultivos, núcleo poblacional, infraestructuras, etc). En todo caso y en general, se pone de manifiesto una pauta de muy amplia artificialización.

Pero el simple cómputo global de un espacio regular de $9 \mathrm{~km}^{2}$ no lo dice todo. Por ello, para conocer con más profundidad la realidad fitogeográfica local, la columna de Flora Común (FC, Tabla 1) aporta información de cuánto ha afectado la secular intervención humana en la cohesión interna de los grupos fitoecológicos dentro de sus subunidades regulares más pequeñas $\left(1 \mathrm{~km}^{2}\right)$. Y es que sólo 134 de las 669 plantas autóctonas están en las nueve cuadrículas. Al respecto cabe pensar que, especialmente, los contingentes florísticos que indican menor degradación ambiental («Ht», «Snn», «Bpe», «Rup», «Asp»y «Bmc») debieran ser relativamente homogéneos en su implantación geográfica primitiva. Sin embargo, el intensivo aprovechamiento de la superficie culminante del páramo para cultivo, entre otros tipos de uso y unidades de paisaje, ha generado una fragmentación tal del paisaje que ha propiciado la desaparición de muchos de aquellos táxones en el continuum espacial. En esos

2 Interpreten y dedúzcanse en las Figuras 1 y 2 las estructuras paisajísticas particulares, y consúltense los comentarios ya efectuados en García-Abad y Panareda (2012, p. 254). 
grandes grupos, ha dado lugar a una descomposición que sólo permite valores inferiores al $27 \%$ de flora común en las unidades anidadas de inferior nivel, llegando incluso a algunas coincidencias casi nulas ( $\ll \mathrm{Snn} » \mathrm{y} \ll \mathrm{Bmc} »)$ o nulas ( $\ll \mathrm{Rup} »)$.

En consecuencia, las plantas ruderal-arvenses se han expandido ampliamente. A este contingente («Hrv»), se unen también otras plantas oportunistas de los grupos «av», «Hm», «Pmh» $\mathrm{y}$ «Msn» en ocupar también espacios abiertos por roturaciones, acondicionamientos agrarios, etc. Todo este conjunto fitoecológico antropogénico, en pequeñas superficies de 1 $\mathrm{km}^{2}$, tiene sin embargo también una ocupación territorial florísticamente irregular y poco cohesionada, con implantación diversa de sus elementos «aquí y allá» (véanse los bajos porcentajes generalizados de FC). Frente a este conjunto, deslavazado espacialmente, sólo aparecen dos grupos con descomposición algo menor (rango 43-37\% de FC): los arbustos y hemicriptófitos vivaces de «Ms» $\mathrm{y}$ «Hbx» están un tanto más cohesionados, porque ocupan biótopos seminaturales de vocación forestal que han sufrido una intensidad fija y continuada de degradación, formando los matorrales y herbazal-matorrales seriales.

\section{II.2. Espectro biotípico de la flora autóctona de AOG y de Miralrío}

En base a los planteamientos y método indicados en García-Abad (2011) para la región de La Alcarria Occidental y Mesa de Ocaña y la clasificación de biótipos de Rivas-Martínez et al. (2007), la Tabla 2 tipifica los biótipos de la flora autóctona de AOG, los de 9C y los de cada una de las cuadrículas por separado. Los datos de esa Tabla 2 se simplifican ${ }^{3}$ y reducen en las Figuras 5 y 6.

Con la referida simplificación, el orden del modelo biotípico que caracteriza a AOG es, como cabía esperar, exactamente el mismo que el determinado para La Alcarria Occidental y Mesa de Ocaña (García-Abad, 2011), aunque destaca el hecho de que los hemicriptófitos (440) casi igualan a los terófitos (456), debido a que buena parte de AOG tiene carácter de submontano a montano:

$$
\mathrm{T}>\mathrm{H}>\mathrm{C}>\mathrm{F}>\mathrm{G}>\mathrm{Hd} \text { y } \mathrm{P}>\mathrm{Hl}>\mathrm{L}
$$

A su vez, el modelo de 9C coincide básicamente con el de AOG, con la poco significativa excepción de que las lianas adelantan un puesto, al equipararse a hidrófitos y pleustófitos y superar a helófitos. Cuantitativamente, la mayor incidencia en espacios reducidos de los efectos de la artificialización antrópica explica unos ligeros descensos relativos de hemicriptófitos, fanerófitos y geófitos debidos al aumento de los terófitos mayoritarios, cuya proporción supera en un $4 \%$ a la alcanzada en la subregión. Por último, la más severa reducción en plantas vinculadas a ambientes acuáticos se explica por la muy pobre presencia de los mismos en 9C.

Si se consideran solamente los cinco primeros términos del modelo biotípico de AOG, se observa que casi todas las cuadrículas por separado se ajustan al mismo. La única excepción efectiva se da en C3, donde fanerófitos y geófitos están igualados. A parte de ello, merecen desta-

3 La simplificación consiste en contabilizar el 50\% de las plantas ambivalentes (con guión) para cada uno de los dos componentes, teniendo en cuenta que Nf, Mif y Msf se agrupan como F (Fanerófitos). Esta operación permite la comparación aproximada con otros territorios, pues en la bibliografía los biótopos aparecen habitualmente por separado. 
Tabla 2

NÚMERO DE PLANTAS AUTÓCTONAS' POR BIÓTIPOS²

\begin{tabular}{|c|c|c|c|c|c|c|c|c|c|c|c|c|c|}
\hline BIÓTIPOOS & AOG & $9 \mathrm{C}$ & C4 & C8 & C2 & C6 & C7 & C9 & C1 & $\mathrm{C} 3$ & C5 & FC & $\%$ \\
\hline $\mathrm{T}$ & 415 & 243 & 167 & 153 & 148 & 128 & 142 & 127 & 138 & 139 & 134 & 50 & 20,5 \\
\hline $\mathrm{H}$ & 384 & 192 & 137 & 132 & 129 & 120 & 102 & 107 & 84 & 89 & 72 & 31 & 16,1 \\
\hline C & 135 & 75 & 62 & 57 & 59 & 51 & 53 & 54 & 58 & 42 & 35 & 28 & 37,3 \\
\hline $\mathrm{H}-\mathrm{T}$ & 81 & 49 & 39 & 35 & 34 & 31 & 29 & 23 & 31 & 31 & 32 & 11 & 22,9 \\
\hline $\mathrm{G}$ & 75 & 33 & 22 & 18 & 16 & 20 & 10 & 18 & 6 & 14 & 5 & 1 & 3,0 \\
\hline $\mathrm{Nf}$ & 33 & 14 & 10 & 11 & 7 & 10 & 9 & 10 & 8 & 8 & 8 & 5 & 35,7 \\
\hline Mif-Nf & 27 & 11 & 6 & 9 & 6 & 11 & 7 & 10 & 5 & 2 & 6 & & \\
\hline C-H & 25 & 9 & 5 & 6 & 6 & 7 & 6 & 7 & 4 & 7 & 3 & 2 & 22,2 \\
\hline Mif & 24 & 14 & 9 & 6 & 5 & 9 & 8 & 7 & 5 & 4 & 4 & 3 & 21,4 \\
\hline $\mathrm{Hd}$ y $\mathrm{P}$ & 24 & 4 & 2 & & 1 & & & 1 & & & & & \\
\hline C-Nf & 16 & 8 & 5 & 5 & 4 & 6 & 6 & 4 & 6 & 2 & 4 & 1 & 12,5 \\
\hline G-H & 9 & 6 & 6 & 2 & 5 & 4 & 4 & 3 & 4 & 2 & 3 & 1 & 16,7 \\
\hline Msf & 7 & 3 & 2 & & & & & & & & 1 & & \\
\hline $\mathrm{L}$ & 5 & 5 & 5 & 4 & 5 & 5 & 3 & 3 & 3 & 1 & 5 & 1 & 20,0 \\
\hline $\mathrm{Hd}-\mathrm{Hl}$ & 5 & 2 & 2 & & 1 & 1 & & & & & & & \\
\hline $\mathrm{HI}$ & 5 & 2 & 1 & 1 & 1 & 1 & & & 1 & & & & \\
\hline
\end{tabular}

${ }^{1}$ Táxones hasta el nivel de variedad. ${ }^{2}$ La consulta de varias floras ha mostrado que, a veces, la adscripción categórica de una planta a uno u otro biótipo es complicada. Por ello hemos preferido mantener la ambigüedad o ambivalencia en el cómputo absoluto. De este modo, cuando aparecen dos abreviaturas separadas por guión, significa que se trata de plantas que pueden presentarse con ambos biótipos indistintamente, o bien que poseen caracteres intermedios entre ellos. ${ }^{3}$ Abreviaturas: C, Caméfitos; G, Geófitos; H, Hemicriptófitos; Hd, Hidrófitos; H1, Helófitos; L, Lianas; Mif, Microfanerófitos; Msf, Mesofanerófitos; Nf, Nanofanerófitos; P, Pleustófitos y T, Terófitos.

Fuentes: AOG (extractadas de García-Abad, 2009), resto (Datos y elaboración propios).

carse dos circunstancias: a) C6 es el recinto que más se ajusta a los valores cuantitativos de AOG, y b) $\mathrm{C} 4$ es el que más se ajusta a los de 9C. El primero presenta una configuración paisajística repartida más o menos equitativamente entre un bosque algo estructurado de encinas y quejigos, tanto en páramo, valle como vaguada de cabecera, y áreas de cultivo en páramo. El segundo es el recinto más geodiverso y el más complejo paisajísticamente, por lo que al ser también el más biodiverso (con 187 terófitos, 162 hemicriptófitos, 67 caméfitos, 31 fanerófitos y 23 geófitos, según cifras simplificadas) confiere buena parte de su impronta florística al conjunto $9 \mathrm{C}$.

La mayor disparidad interna de $9 \mathrm{C}$ entre las subunidades de $1 \mathrm{~km}^{2}$ se presenta en el porcentaje de terófitos y en la ratio terófitos/hemicriptófitos, en función de los distintos niveles de alteración y fragmentación del paisaje primigenio en las cuadrículas. De este modo, obviamente C5 es el recinto con mayor diferencia entre ambos componentes (151 terófitos frente a 91 hemicriptófitos), por su mayor alejamiento respecto a la naturalidad y por su correspondiente mayor porcentaje de terófitos (casi la mitad de todas las plantas); mientras que, opuestamente, en la vecina C6 ambos están casi igualados (144 frente a 140) y, además, es el recinto con mayor proporción de fanerófitos y de geófitos. Por otro lado, se destaca lo siguiente: a) $\mathrm{C} 1$, con apenas una pequeña parte de bosque abierto pero bastantes matorrales, sobresale por su mayor proporción de caméfitos (hasta 63, número equiparable al de las cuadrículas más biodiversas), y b) donde el bosque falta, es minoritario o está abierto, el porcentaje de geófitos es menor (C5, C1 y C7 tienen menos de 13). 
Figura 5

ESPECTRO BIOTÍPICO DE LAS PLANTAS DE LAALCARRIA OCCIDENTAL DE GUADALAJARA

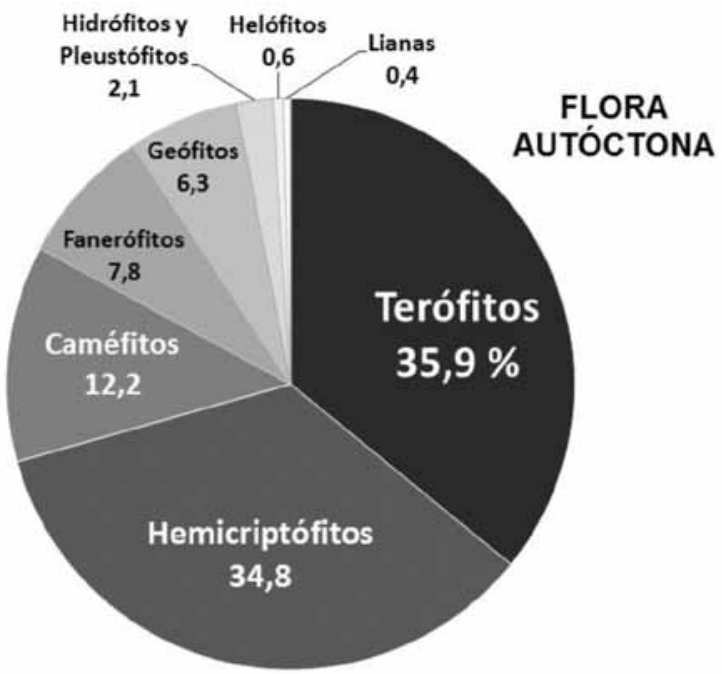

Fuente: García-Abad (2009, datos extractados para AOG). Elaboración propia.

Figura 6

ESPECTROS COMPARADOS DE LOS BIÓTIPOS DE LAS NUEVE CUADRÍCULAS DE 1×1 KM Y DEL CONJUNTO FLORAL 9C DE 3×3 KM (COLUMNA NEGRA)

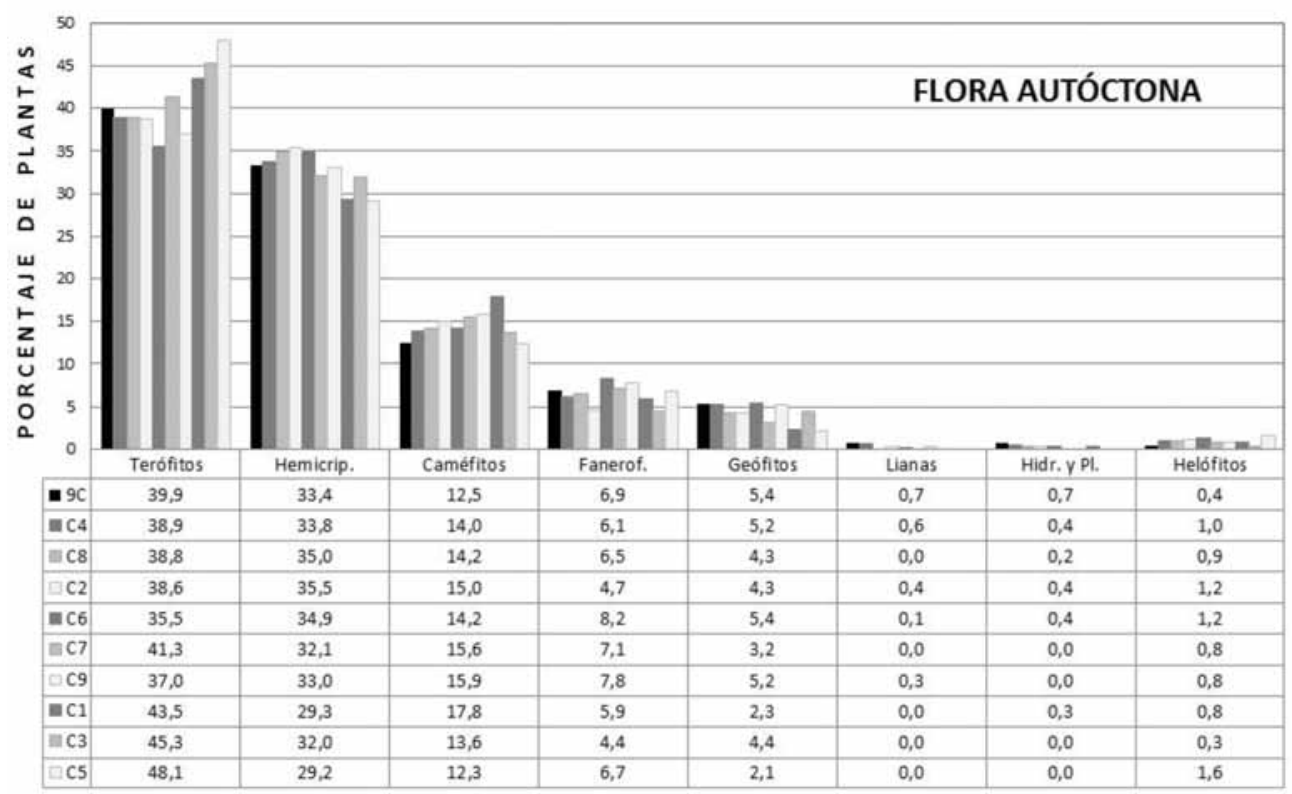

Fuente: Datos y elaboración propios. 
En cuanto a la Flora Común de 9C, con los datos no simplificados de la Tabla 2, internamente son los caméfitos y nanofanerófitos los elementos menos disímiles entre cuadrículas, frente al extremadamente disímil componente geofítico. Aunque ya menos, los hemicriptófitos también son elementos discordantes. Y, finalmente, los terófitos menos aún, pero lejos todavía de la mínima disimilitud de aquellos elementos de mayor fitomasa.

Una cuestión muy vinculada con las formas vitales es la pervivencia de la planta. De este modo, los biótipos de la Tabla 2 se han agrupado en la Figura 7 en tres categorías muy sintéticas, con objeto de exponer las proporciones en cada nivel territorial de anidamento.

Figura 7

ESPECTRO VEGETATIVO DE PERVIVENCIA DE LA PLANTA

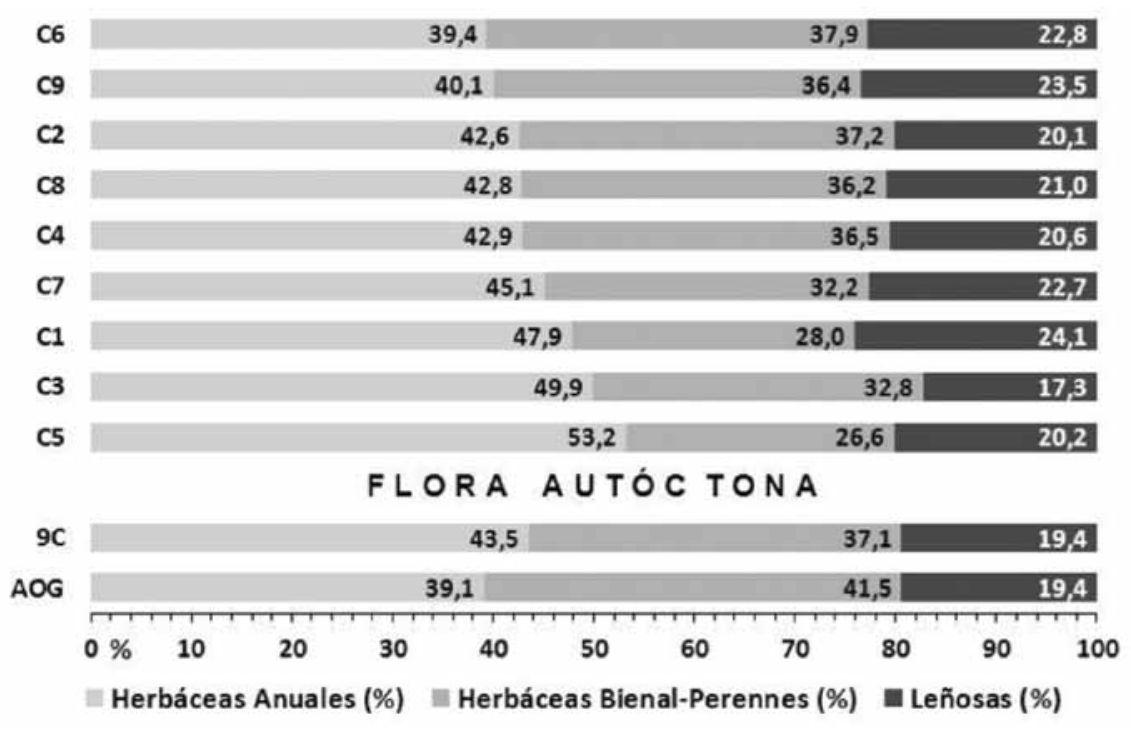

NOTAS: A) Los cómputos se han realizado agrupando los datos de la Tabla 2, teniendo en cuenta el comportamiento vegetativo dominante fundamental y sin importar algunas excepciones por ser éstas poco relevantes cuantitativamente (herbáceas siempre o casi siempre anuales: T y H-T, herbáceas predominantemente bienal-perennes: H, G-H, H, C-H, Hd y P, Hd-Hl y Hd, y plantas siempre o casi siempre leñosas: C, C-Nf, L, Nf, Nf-Mif, Mif y Msf). B) Las cuadrículas de $1 \times 1 \mathrm{~km}$ aparecen, de arriba a abajo, ordenadas de menor a mayor porcentaje de Herbáceas Anuales. Fuentes: AOG (extractadas de García-Abad, 2009), resto (Datos y elaboración propios).

Según este criterio, sin considerar cuestiones de detalle, se obtiene que: a) el porcentaje de leñosas de $9 \mathrm{C}$ coincide del todo con el de AOG, lo que muestra que en Miralrío las plantas propias de matorrales, arbustedas y bosques son plenamente representativas de las correspondientes del paisaje vegetal alcarreño; b) la mayor artificialización relativa del conjunto 9C respecto a la típica de AOG (muy evidente en las tres cuadrículas inferiores de la Figura 7) se manifiesta en un ligero pero claro aumento de herbáceas anuales equivalente al descenso de herbáceas bienal-perennes; c) como correlato, cuanto mayor es la presencia de ambientes semi-naturales en las cuadrículas, mayor es el porcentaje de herbáceas bienal- 
perennes y menor el de herbáceas anuales; d) C6 vuelve a ser la cuadrícula que más se ajusta a los valores de AOG; y e) los espectros de las tres cuadrículas con mayor riqueza florística $(\mathrm{C} 2, \mathrm{C} 4$ y $\mathrm{C} 8)$ son prácticamente iguales.

\section{II.3. Espectro biogeográfico de la flora autóctona de AOG y de Miralrío}

El biogeográfico (o corológico) es uno de los espectros habituales en Fitogeografía (Costa, 1997, Meaza, 2000). La Tabla 3 presenta sintetizada en agrupaciones geográficas la flora autóctona de AOG, la del conjunto 9C y la de cada una de las cuadrículas por separado, según aquel criterio. Se aplica de modo general el sistema biogeográfico de Mateo y Crespo (2002), adaptando alguna nomenclatura y completado por otras fuentes complementarias: Bolòs y Vigo (1984-2001), Castroviejo (1986-2008), FLORA IBERICA (web), ANTHOS (web) y ATLAS DE LA FLORA DE ARAGÓN (web). Los datos de esa Tabla 3 se reducen en las Figuras 8 y 9, empleando agrupaciones aún más sintéticas.

Al tratarse de un territorio plenamente mediterráneo desde un punto de vista bioclimático, AOG tiene una flora claramente liderada por plantas cuya distribución corresponde a distintos tipos de áreas, más o menos amplias, pero que ciñen sus límites geográficos a los propios del clima mediterráneo (casi el 30\%). En segundo lugar, le sigue un agrupamiento hasta cierto punto también mediterráneo, pero más amplio pues sobrepasa aquellos límites estrictos (casi el 23\%). Y, en tercer lugar, el elemento endémico ibérico-balear supone casi una undécima parte de todas las plantas (casi el 9\%). Así pues, estos tres grupos vinculados más o menos a la mediterraneidad son los claramente mayoritarios.

Pero, para visualizar con más claridad el alcance del cumplimiento de esta pauta fundamental, conviene agrupar los diferentes componentes mediterráneos y compararlos combinadamente con el resto (supra y extramediterráneos). Así, en la Figura 10 se presentan cuatro agrupaciones que permiten una integración eurioica progresiva, indicando porcentajes parciales y acumulados.

Aunque AOG posee, efectivamente, un componente florístico mediterráneo amplio mayoritario (61\%), al que 9C no se sustrae (60,5\%); sin embargo, este liderazgo lo pierde si se prefiere comparar el componente mediterráneo estricto (endemismos y estenomediterráneo) con el extra/supramediterráneo (38,3 frente al 39,1\%). En esta comparación, 9C pierde incluso aún más peso mediterráneo estricto (34,5 frente al 39,5\%). De este modo, tanto en AOG como en 9C los elementos florísticos extra y supramediterráneos adquieren ya una destacada importancia relativa, pues lideran el modelo corológico cuando del componente mediterráneo amplio se separa el eurimediterráneo. El matiz continentalizador del clima mediterráneo, por su situación en el centro peninsular, junto con los fríos algo más severos del invierno, por el carácter montano-submontano que imprime la altitud de los páramos alcarreños por encima de los 1.000 m s.n.m., explican esta caracterización biogeográfica de la subregión.

Así pues, el orden corológico sintético de AOG tiene el siguiente modelo (Figura 10):

$$
\text { Supra/extramediterráneo }>\text { Estenomediterráneo }>\text { Eurimediterráneo }>\text { Endemismos }
$$


Tabla 3

NÚMERO DE PLANTAS AUTÓCTONAS (HASTA VARIEDAD) SEGÚN DISTRIBUCIÓN GEOGRÁFICA

\begin{tabular}{|c|c|c|c|c|c|c|c|c|c|c|c|c|c|}
\hline $\begin{array}{c}\text { DISTRIBUCIÓN } \\
\text { GEOGRÁFICA }\end{array}$ & AOG & 9C & $\mathrm{C} 4$ & C8 & $\mathrm{C} 2$ & C6 & C7 & C9 & C1 & C3 & C5 & FC & $\%$ \\
\hline $\begin{array}{l}\text { Endemismo Ibérico } \\
\text { (Centro) }\end{array}$ & 12 & 2 & 1 & 1 & 2 & 1 & 1 & 1 & 1 & 1 & & & \\
\hline $\begin{array}{l}\text { End. Ibérico-Balear } \\
\text { (C, S y E) }\end{array}$ & 35 & 10 & 5 & 6 & 5 & 4 & 5 & 4 & 3 & 5 & 3 & 1 & 10,0 \\
\hline $\begin{array}{l}\text { End. Ibérico-Balear } \\
\text { amplio/disperso }\end{array}$ & 63 & 26 & 18 & 18 & 18 & 21 & 18 & 15 & 20 & 18 & 8 & 5 & 19,2 \\
\hline $\begin{array}{l}\text { Endemismos } \\
\text { Ibérico-Baleares }\end{array}$ & 110 & 38 & 24 & 25 & 25 & 26 & 24 & 20 & 24 & 24 & 11 & 6 & 15,8 \\
\hline $\begin{array}{l}\text { Estenomediterránea } \\
\text { Suroccidental }\end{array}$ & 80 & 29 & 17 & 21 & 16 & 17 & 13 & 15 & 12 & 12 & 10 & 6 & 20,7 \\
\hline $\begin{array}{l}\text { Estenomediterranea } \\
\text { Noroccidental }\end{array}$ & 37 & 18 & 9 & 13 & 12 & 7 & 13 & 11 & 9 & 7 & 6 & 5 & 27,8 \\
\hline $\begin{array}{l}\text { Estenomediterránea } \\
\text { Occidental }\end{array}$ & 108 & 60 & 41 & 45 & 35 & 43 & 37 & 44 & 39 & 28 & 27 & 14 & 23,3 \\
\hline $\begin{array}{l}\text { Estenomediterránea } \\
\text { Meridional }\end{array}$ & 7 & 3 & 1 & 1 & & & 1 & & 1 & & & & \\
\hline $\begin{array}{l}\text { Estenomediterránea } \\
\text { Septentrional }\end{array}$ & 11 & 6 & 4 & 3 & 3 & 2 & 3 & 3 & 2 & 3 & 2 & 1 & 16,7 \\
\hline Estenomediterránea & 133 & 77 & 55 & 56 & 53 & 52 & 45 & 54 & 50 & $48^{-}$ & 40 & 19 & 24,7 \\
\hline Eurimediterránea & 267 & 164 & 120 & 105 & 107 & 104 & 100 & 88 & 89 & 91 & 88 & 36 & 22,0 \\
\hline $\begin{array}{l}\text { Mediterránea y } \\
\text { Atlántica }\end{array}$ & 21 & 10 & 7 & 5 & 6 & 5 & 6 & 8 & 5 & 4 & 4 & 4 & 40,0 \\
\hline $\begin{array}{l}\text { Mediterránea } \\
\text { (amplia) }\end{array}$ & 664 & 367 & 254 & 249 & 232 & 230 & 218 & 223 & 207 & 193 & 177 & 85 & 23,2 \\
\hline Europea & 30 & 14 & 12 & 13 & 13 & 11 & 10 & 11 & 9 & 12 & 10 & 4 & 28,6 \\
\hline Eurosiberiana y Boreal & 30 & 9 & 8 & 4 & 5 & 3 & 5 & 3 & 4 & 2 & 2 & & \\
\hline $\begin{array}{l}\text { Eurieurosiberiana y } \\
\text { Euriboreal }\end{array}$ & 54 & 31 & 22 & 20 & 18 & 18 & 14 & 17 & 10 & 11 & 12 & 2 & 6,5 \\
\hline $\begin{array}{l}\text { Eurieuropea y } \\
\text { Perieuropea }\end{array}$ & 105 & 56 & 45 & 36 & 36 & 34 & 31 & 35 & 31 & 31 & 27 & 12 & 21,4 \\
\hline $\begin{array}{l}\text { Peri-/Eurieuropea y } \\
\text { Europea }\end{array}$ & 219 & 110 & 87 & 73 & 72 & 66 & 60 & 66 & 54 & 56 & 51 & 18 & 16,4 \\
\hline Euroasiática & 48 & 25 & 16 & 18 & 16 & 16 & 10 & 14 & 10 & 11 & 12 & 4 & 16,0 \\
\hline Eurieuroasiática & 88 & 62 & 49 & 39 & 40 & 33 & 37 & 26 & 30 & 34 & 30 & 11 & 17,7 \\
\hline Paleotemplada & 6 & 4 & 2 & 4 & 1 & 3 & 1 & 3 & 1 & & 1 & & \\
\hline Holoártica & 54 & 28 & 22 & 14 & 16 & 12 & 12 & 11 & 10 & 9 & 10 & 4 & 14,3 \\
\hline $\begin{array}{l}\text { Plurirregional y } \\
\text { Euripantropical }\end{array}$ & 22 & 10 & 8 & 4 & 7 & 6 & 5 & 4 & 4 & 4 & 5 & 3 & 30,0 \\
\hline Subcosmopolita & 36 & 18 & 13 & 7 & 13 & 7 & 6 & 3 & 8 & 7 & 10 & 1 & 5,6 \\
\hline Cosmopolita & 12 & 4 & 4 & 4 & 3 & 3 & 4 & 2 & 3 & 2 & 4 & 2 & 50,0 \\
\hline $\begin{array}{l}\text { Supraeuropea } \\
\text { Amplia }\end{array}$ & 266 & 152 & 115 & 91 & 97 & 80 & 75 & 63 & 66 & 68 & 73 & 25 & 16,4 \\
\hline $\begin{array}{l}\text { Desconocida o } \\
\text { Incierta }\end{array}$ & 11 & 3 & 1 & 2 & 2 & 2 & 2 & 2 & 2 & 1 & 1 & & \\
\hline
\end{tabular}

NOTA: Las distribuciones aparecen, de arriba a abajo, en orden aproximado de mayor estenoicidad a mayor eurioicidad. Fuentes: AOG (extractadas de García-Abad, 2009), resto (Datos y elaboración propios). 
El conjunto 9C sigue el mismo modelo, pero con el desajuste cuantitativo de que la baja presencia relativa de endemismos, por su aún reducido espacio, se compensa con la mayor proporción de elementos eurimediterráneos.

Casi todas las cuadrículas por separado presentan el mismo modelo, salvo algunas pocas excepciones y matices: a) en la cuadrícula más extremadamente artificializada (C5) los elementos eurimediterráneos superan a los estenomediterráneos; b) dos cuadrículas tienen igual proporción (C4) o casi igual (C3) de ambos elementos; c) la presencia de plantas neutro/ acidófilas y cierta concentración de rupestres, entre otras circunstancias, hacen que C9 posea la mayor proporción de elementos estenomediterráneos, tantos que casi iguala a la de supra/ extramediterráneos; d) las cuadrículas surorientales (C8, C6 y C9), por la exposición solana más generalizada de sus vertientes, son las más mediterráneas $(\mathrm{C} 8$, por ejemplo, alberga 164 plantas endémicas y estenomediterráneas, mientras que la más rica C4 sólo 151); y e) frente a ellas, las noroccidentales $\mathrm{C} 4$ y $\mathrm{C} 2$, con vallezuelos bastante encajados y resguardados, concentran el mayor número de elementos supra/extramediterráneos (203 y 171, respectivamente, frente a la horquilla 166-131 de las tres cuadrículas anteriores). Uno de los factores que explican en parte alguna de estas salvedades es que la artificialización/antropización del paisaje afecta a una mayor pérdida relativa de elementos supra/extramediterráneos (sobre todo, distribuciones eurosiberiano-boreales), pero menos a los mediterráneos amplios, tal y como se comprueba sobre todo en $\mathrm{C} 1, \mathrm{C} 3$ y $\mathrm{C} 7$.

En relación al interesante grupo de endemismos ibérico-baleares, en AOG éstos involucran a 29 familias, siendo 18 compuestas, 13 labiadas, 11 cariofiláceas, 11 crucíferas y 10 escrofulariáceas. Ningún endemismo lo es del estricto territorio de AOG, de modo que esta subregión no constituye un espacio florístico particularizado. En todo caso, hay cuatro táxones cuya procedencia originaria se extiende algo más allá de AOG por el Sur o/y por el Este: Limonium erectum, L. dichotomum, Helianthemum marifolium subsp. conquensis y Brassica repanda subsp. gypsicola, con distribución conjunta manchega, obispaleña, altoalcarreña o/y bajomatritense (Rivas-Martínez, 2007).

En el conjunto 9C, con 38 endemismos ibérico-baleares, el porcentaje de estos $(5,7 \%)$ es, obviamente, bastante más bajo que el subregional debido a su reducida extensión. Pero, por esto mismo y porque se han encontrado el 34,5\% de los 110 los endemismos existentes en AOG, el área de Miralrío puede considerarse en términos relativos bien nutrida de este tipo de elementos florísticos. Como endemismos más restringidos espacialmente, sólo se encontraron dos táxones relevantes por su procedencia exclusiva del centro peninsular: Centaurea toletana var. cavanillesiana y Genista pumila subsp. rigidissima.

En cuanto a las cuadrículas por separado, alcanzan una media de 22,6 plantas endémicas por kilómetro cuadrado, es decir un promedio del 20,5\% de todas las presentes en AOG. En la Tabla 3 se aprecia cómo el rango absoluto oscila entre 26 y 11 endemismos, pero si se excluye C5 por su extremada artificialización, al menos se hallarían 20 en el resto de cuadrículas. Salvo este condicionante extraordinario, no se encuentra ninguna otra pauta de variación en el número de endemismos dentro de 9C. Compuestas y labiadas son las familias con más peso relativo entre ellos.

La columna de Flora Común (Tabla 3) muestra muy poca cohesión de los diferentes agregados corológicos en 9C, sobre todo del conjunto supra-extramediterráneo. 
Figura 8

ESPECTRO BIOGEOGRÁFICO DE LAS PLANTAS DE LAALCARRIA OCCIDENTAL DE GUADALAJARA

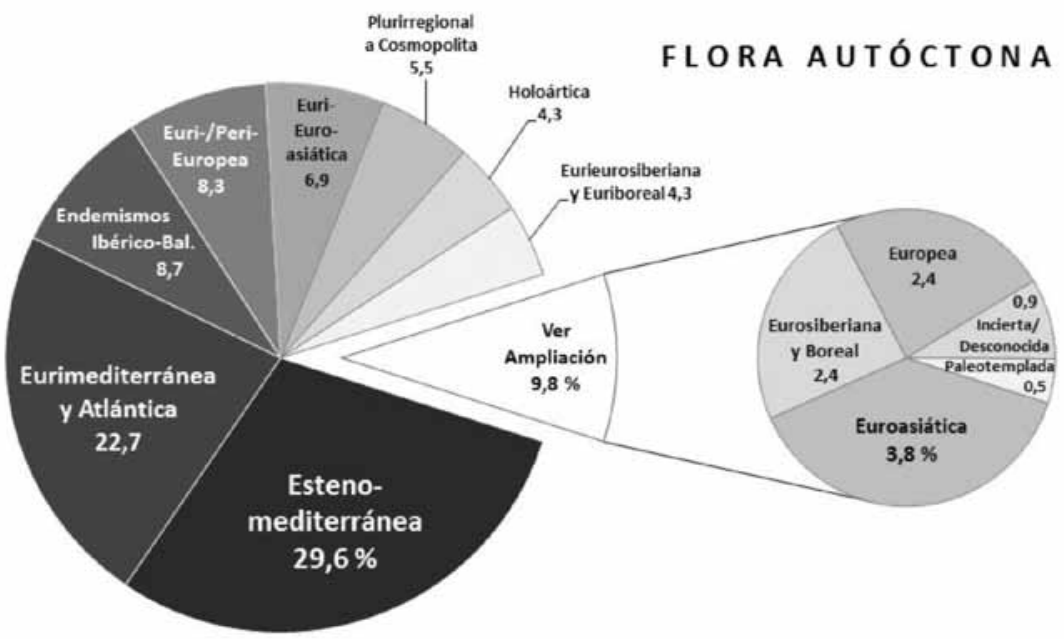

Fuente: García-Abad (2009, datos extractados para AOG). Elaboración propia.

Figura 9

ESPECTROS BIOGEOGRÁFICOS ${ }^{1}$ COMPARADOS DE LAS NUEVE CUADRÍCULAS DE 1×1 KM Y DEL CONJUNTO FLORAL $9 C$ DE $3 \times 3$ KM (COLUMNA NEGRA)

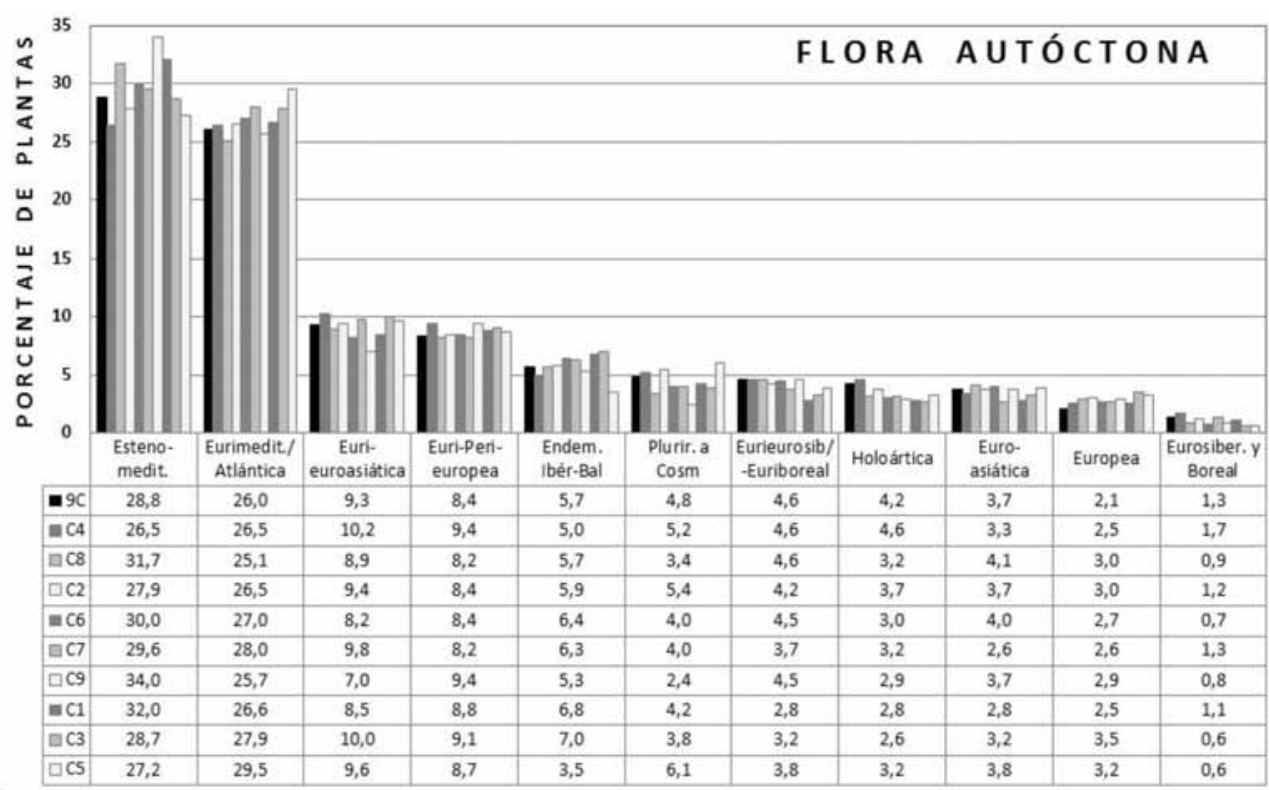

${ }^{1}$ Se representan las once agrupaciones de distribución más importantes. Fuente: Datos y elaboración propios 
Figura 10

GRUPOS MÁS GENERALES DE DISTRIBUCIÓN GEOGRÁFICA

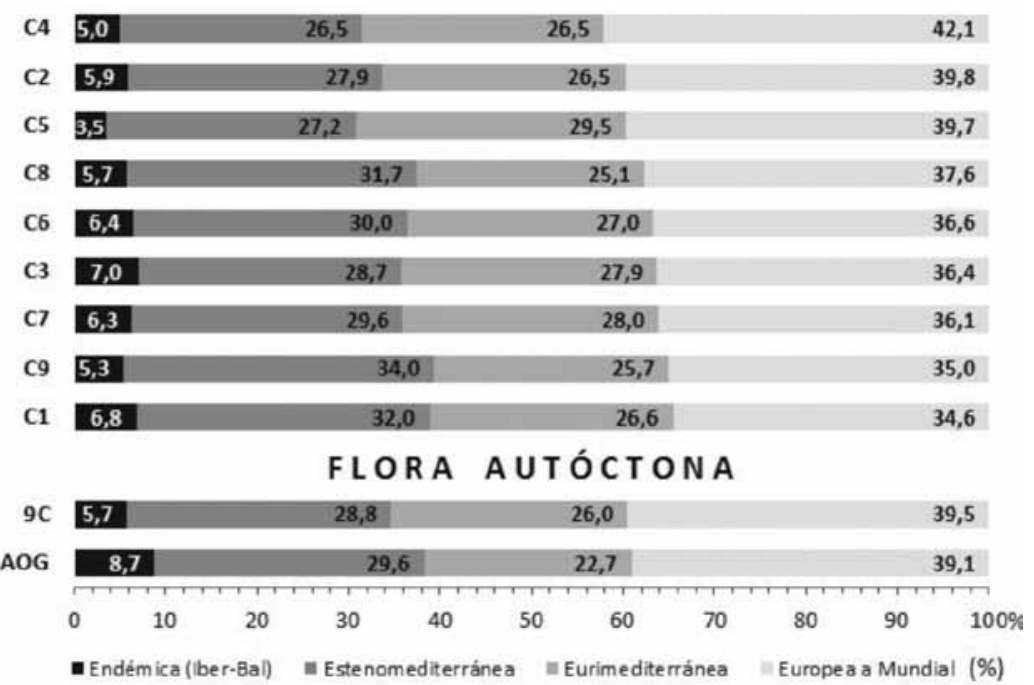

NOTA: Las cuadrículas de $1 \times 1 \mathrm{~km}$ aparecen, de arriba a abajo, ordenadas de mayor a menor porcentaje de plantas con distribución extra/supramediterránea (Europea a Mundial) o, dicho de otro modo, de menor a mayor mediterraneidad. Fuentes: las mismas de la Tabla 3. Elaboración propia.

\section{II.4. Flora alóctona de La Alcarria Occidental de Guadalajara y de Miralrío}

A continuación se abordarán los espectros de las plantas alóctonas, lo que implica adentrarse en la realidad fitogeográfica cultural. Las plantas foráneas de Miralrío se expusieron en el listado del trabajo precedente (García-Abad y Panareda, 2012). Una vez analizada la procedencia de las plantas, la Tabla 4 muestra el desglose numérico elemental entre plantas autóctonas y alóctonas.

Se observa un significativo peso de alóctonas en AOG, pues son casi una décima parte de las plantas (hay 1 alóctona por cada 9,3 autóctonas). El conjunto 9C presenta un nivel un poco menor (sube la Ratio). Sin embargo, casi todas las cuadrículas por separado tienen niveles aún menores (simple anécdota, en C9). Las cuadrículas relativamente más antropizadas son C4, C5, C7 y C2.

Se aprecia claramente cómo el contingente xenofítico se concentra en las proximidades del núcleo de Miralrío (C4) donde hay bastantes plantas foráneas. Están vinculadas básicamente al complejo hortelano alimentado por enclaves fontanales de las laderas del Vallezuelo de Cáritas, a la presencia en él de algunas parcelas y al entorno periférico del pueblo (naves, eras, área recreativo-ajardinada, etc). Desde un punto de vista fitoecológico la flora alóctona pone de manifiesto que la pauta de cultivo agrícola y malas hierbas asociadas es la principal y dominante. Si se agregan plantas cultivadas y malas hierbas foráneas compondrían en torno a las dos terceras partes de todas las alóctonas tanto en $\mathrm{AOG}$ como en 9C, cumpliendo $\mathrm{C} 1$, C3, C4 y C7 unas pautas porcentuales similares. Y es que la subregión está influida por una agricultura tradicional: rosáceas frutícolas (destaca Prunus spp.), leñosas de la tríada medite- 
rránea (Olea europaea, Vitis vinifera), Juglans regia y Ficus carica. Están acompañados por neófitos herbáceos ampliamente generalizados por esa actividad agrícola (Amaranthus spp., Xanthium spp., entre otros). Sin embargo, se observó que la afección de alóctonas fue casi nula en los espacios semi-naturales de matorrales, monte bajo y bosques (la única excepción fue la presencia esporádica de Medicago sativa). Y, en las olmedas y praderas meso-higrófilas, los observados fueron tan sólo Asperugo procumbens y Rubia tinctorum.

Tabla 4

NÚMERO DE PLANTAS (HASTA RANGO DE VARIEDAD, Y CON HÍBRIDOS), SEGÚN AUTOCTONÍA/ALOCTONÍA

\begin{tabular}{|c|c|c|c|c|}
\hline Unidades & Autóctonas & Alóctonas & (1) Ratio & TOTAL \\
\hline C4 & 480 & 46 & 10,4 & 526 \\
\hline C5 & 312 & 21 & 14,9 & 333 \\
\hline C7 & 380 & 22 & 17,3 & 402 \\
\hline $\mathrm{C} 2$ & 429 & 23 & 18,7 & 452 \\
\hline $\mathrm{C3}$ & 342 & 15 & 22,8 & 357 \\
\hline $\mathrm{C8}$ & 439 & 19 & 23,1 & 458 \\
\hline C6 & 404 & 17 & 23,8 & 421 \\
\hline C1 & 353 & 12 & 29,4 & 365 \\
\hline C9 & 374 & 6 & 62,3 & 380 \\
\hline 9C & 673 & 61 & 11,0 & 734 \\
\hline AOG & 1283 & 138 & 9,3 & (2) 1421 \\
\hline
\end{tabular}

(1) Número de plantas alóctonas (AL) por cada planta autóctona (AU); Ratio=AU/AL. (2) A las 1365 plantas reportadas en García-Abad y Panareda (2012, p. 251) se añaden 15 autóctonas hasta el rango de variedad, 14 híbridos y otras 27 leñosas o herbáceas vivaces más que se cultivan o han sido cultivadas para fines agrícolas, ornamentales u otros. No se contemplan, por tanto, las numerosas plantas herbáceas cultivadas, salvo cuando las hayamos encontrado o existan referencias de ellas asilvestradas, escapadas de cultivo en hábitat diferentes al del propio cultivo o en años posteriores al mismo. NOTA: Las cuadrículas de $1 \times 1 \mathrm{~km}$ aparecen, de arriba a abajo, ordenadas de menor a mayor Ratio AU/AL. Fuentes: AOG (extractadas de García-Abad, 2009), resto (Datos y elaboración propios)

La Tabla 5 muestra el espectro taxonómico de la flora alóctona. En AOG, las tres primeras familias que lideran en términos relativos la flora alóctona son las mismas que lideran la flora autóctona (García-Abad y Panareda, 2012), pero con la diferencia de que compuestas y leguminosas están equiparadas y, por otro lado, las gramíneas, igualadas con las rosáceas, pasan a ocupar el tercer lugar. Compuestas y gramíneas, por tanto, experimentan una cierta pérdida del protagonismo que tenían entre las autóctonas, contrariamente a lo que ocurre con leguminosas y, sobre todo, rosáceas, que superan en más del doble el porcentaje que ostentaban en la flora autóctona.

El espectro taxonómico tipo de la flora alóctona en AOG es el siguiente:

$$
\mathrm{Com}=\mathrm{Leg}>\mathrm{Gram}=\mathrm{Ros}>\mathrm{Ama}=\mathrm{Sol}=\mathrm{Cuc} \approx \mathrm{Ole}^{4}
$$

Puede apreciarse cómo en las foráneas aparecen tres familias que eran muy minoritarias entre las nativas: amarantáceas (los bledos ya referidos), solanáceas y cucurbitáceas. Las gimnospermas ocupan también un lugar relativamente más destacado respecto al espectro autóctono. Los géneros

4 Estas ocho familias suponen casi el 50\% de toda la flora alóctona. 
con mayor número de plantas alóctonas en AOG son, por orden decreciente, los siguientes: Amaranthus (6 especies), Prunus (5), Xanthium (4), Acer (3), Cucumis (3), Pinus (3) y Populus (3).

En 9C el modelo de AOG sufre algún desajuste, aunque en general marca una misma pauta. Destacan el liderazgo de las rosáceas (árboles frutales), la menor presencia relativa de gramíneas y la ausencia de cucurbitáceas ${ }^{5}$. En las cuadrículas por separado destacan: a) máxima concentración en un único foco geográfico (C4), tal y como se había adelandado; b) las amarantáceas mantienen un número similar de presencia en casi todas las cuadrículas; c) con excepción del olivo cultivado/asilvestrado, las plantas más comunes en ellas corresponden a naturalizadas; d) la alfalfa silvestre (Medicago sativa) es la única en las nueve cuadrículas; Amaranthus albus, A. blitoides, A. retroflexus y Crepis alpina están en ocho, y Asperugo procumbens y Veronica polita están en siete; e) compuestas y leguminosas son las únicas familias que siempre tienen algún representante en todas las cuadrículas; y f) vinculado a lo anterior, esta flora xenofítica tiene muy poca cohesión y presenta gran dispersión en las diferentes cuadrículas, tal como indica el dato de que el $46 \%$ estén en una sola cuadrícula; y, además, en bastantes casos son especialmente muy pocos o únicos los pies existentes (Ligustrum lucidum, Acer spp., Corylus avellana, Populus $\times$ canadensis, Cupressus spp., Mirabilis jalapa, Syringa vulgaris, Cydonia oblonga, Morus spp., Pyrus cordata, Pinus spp., Spartium junceum y Tamarix sp.). Una de las razones de esta realidad es el carácter ornamental que poseen varios de estos táxones.

Tabla 5

NÚMERO DE TÁXONES Y NOTHOTÁXONES ALÓCTONOS POR GRUPOS TAXONÓMICOS

\begin{tabular}{|c|c|c|c|c|c|c|c|c|c|c|c|}
\hline GRUPOS & AOG & $9 \mathrm{C}$ & $\mathrm{C4}$ & $\mathrm{C} 2$ & $\mathrm{C} 7$ & C5 & C8 & C6 & C3 & C1 & C9 \\
\hline Gymnospermae & $4(2)^{*}$ & $\begin{array}{c}4 \\
(2)\end{array}$ & $\begin{array}{c}2 \\
(1)\end{array}$ & & & $\begin{array}{c}1 \\
(1)\end{array}$ & & & & $\begin{array}{c}1 \\
(1)\end{array}$ & \\
\hline Dicotiledones & $\begin{array}{l}117 \\
(49)\end{array}$ & $\begin{array}{r}53 \\
(25)\end{array}$ & $\begin{array}{c}42 \\
(22)\end{array}$ & $\begin{array}{c}22 \\
(14)\end{array}$ & $\begin{array}{c}22 \\
(12)\end{array}$ & $\begin{array}{c}18 \\
(11)\end{array}$ & $\begin{array}{c}19 \\
(12)\end{array}$ & $\begin{array}{c}17 \\
(13)\end{array}$ & $\begin{array}{l}14 \\
(9)\end{array}$ & $\begin{array}{l}11 \\
(8)\end{array}$ & $\begin{array}{c}6 \\
(6)\end{array}$ \\
\hline Compositae & 12 & 7 & 5 & 3 & 4 & 2 & 3 & 2 & 3 & 1 & 1 \\
\hline Leguminosae & 12 & 5 & 3 & 2 & 4 & 2 & 2 & 1 & 1 & 1 & 1 \\
\hline Rosaceae & 11 & 8 & 7 & 3 & 3 & 2 & & 2 & 2 & 2 & 1 \\
\hline Amaranthaceae & 6 & 5 & 4 & 3 & 3 & 3 & 4 & 3 & 3 & 3 & \\
\hline Solanaceae & 6 & 2 & 1 & & & 1 & & & & & \\
\hline Cucurbitaceae & 6 & & & & & & & & & & \\
\hline Oleaceae & 5 & 3 & 3 & 1 & 1 & & 1 & 1 & & 1 & 1 \\
\hline Salicaceae & 4 & 2 & 1 & 1 & 1 & & 1 & 1 & & & \\
\hline Resto de Familias & 55 & 21 & 18 & 9 & 6 & 8 & 8 & 7 & 5 & 3 & 2 \\
\hline Monocotiledones & $\begin{array}{l}17 \\
(5)\end{array}$ & $\begin{array}{c}4 \\
\text { (2) }\end{array}$ & $\begin{array}{c}2 \\
(1)\end{array}$ & $\begin{array}{c}1 \\
(1)\end{array}$ & & $\begin{array}{c}2 \\
(2)\end{array}$ & & & $\begin{array}{c}1 \\
(1)\end{array}$ & & \\
\hline Gramineae & 11 & 3 & 2 & 1 & & 1 & & & 1 & & \\
\hline Resto de Familias & 6 & 1 & & & & 1 & & & & & \\
\hline Hasta Familia & 56 & 29 & 24 & 15 & 12 & 14 & 12 & 13 & 10 & 9 & 6 \\
\hline H. Género & 108 & 45 & 39 & 18 & 19 & 18 & 16 & 15 & 13 & 9 & 6 \\
\hline H. Esp/Sub/Var & 138 & 61 & 46 & 23 & 22 & 21 & 19 & 17 & 15 & 12 & 6 \\
\hline
\end{tabular}

* Entre paréntesis aparece el número de familias. NOTAS: Las cuadrículas de $1 \times 1 \mathrm{~km}$ aparecen, de derecha a izquierda, en orden descendente en el número de plantas alóctonas.

Fuentes: AOG (extractadas de García-Abad, 2009), resto (Datos y elaboración propios).

5 Terófitos cultivados habitualmente en las huertas (calabacines, calabazas, pepinos, melones, sandías, etc), que muy pocas veces se asilvestran y que, en nuestro caso, no se encontraron mientras se desarrolló la prospección florística. 
El espectro biotípico de la flora alóctona difiere mucho del de la flora autóctona. Los datos absolutos se muestran en la Tabla 6. Aunque los terófitos, biótipo líder de la flora autóctona, aumentan su porcentaje en la alóctona $(39,1 \%)$, son relegados por el liderazgo de los fanerófitos $(39,9 \%)$, que experimentan un muy considerable aumento. Éste va en detrimento de hemicriptófitos $(10,9 \%)$, geófitos $(5,1 \%)$ y caméfitos $(3,6 \%)$, que merman su proporción respecto a los autóctonos. Efectivamente, son arbolillos y árboles introducidos por el hombre de manera premeditada, fundamentalmente para uso ornamental y de cultivo agrícola, los que provocan este importante vuelco. En todo caso, entre las alóctonas que llegaron a AOG de manera fortuita o no premeditada (naturalizadas, en líneas generales), el biótipo más importante es con diferencia el de los terófitos.

Tabla 6

NÚMERO DE PLANTAS ALÓCTONAS POR BIÓTIPOS(CON HÍBRIDOS)

\begin{tabular}{|c|c|c|c|c|c|c|c|c|c|c|c|}
\hline BIÓTIPOS & AOG & $9 \mathrm{C}$ & $\mathrm{C4}$ & C2 & $\mathrm{C}^{7}$ & C5 & C8 & C6 & C3 & C1 & C9 \\
\hline $\mathrm{T}$ & 52 & 18 & 13 & 11 & 9 & 11 & 8 & 7 & 10 & 6 & 2 \\
\hline Mif & 19 & 12 & 12 & 5 & 4 & 2 & 2 & 3 & 2 & 1 & \\
\hline Mif-Nf & 12 & 7 & 5 & 1 & 1 & 1 & 2 & 2 & & 1 & 2 \\
\hline $\mathrm{H}$ & 11 & 6 & 5 & 4 & 2 & 2 & 4 & 3 & 1 & 1 & 2 \\
\hline Msf & 9 & 4 & 2 & & 2 & 2 & 1 & & 1 & & \\
\hline Maf-Msf & 8 & 4 & 3 & 2 & 1 & 1 & 1 & 2 & 1 & 1 & \\
\hline G & 6 & 1 & & & & 1 & & & & & \\
\hline Mif-Msf & 5 & 3 & 3 & & 2 & 1 & & & & 1 & \\
\hline $\mathrm{C}$ & 4 & 1 & 1 & & & & & & & & \\
\hline $\mathrm{H}-\mathrm{T}$ & 4 & & & & & & & & & & \\
\hline $\mathrm{C}-\mathrm{H}$ & 2 & 2 & & & 1 & & 1 & & & & \\
\hline Maf & 2 & 2 & 1 & & & & & & & 1 & \\
\hline G-H & 2 & 1 & 1 & & & & & & & & \\
\hline L & 2 & & & & & & & & & & \\
\hline
\end{tabular}

NOTAS: A) Maf, Macrofanerófitos; el resto de abreviaturas son las mismas que las de la Tabla 2. B) Las cuadrículas de $1 \times 1 \mathrm{~km}$ aparecen, de derecha a izquierda, en orden descendente en el número de plantas alóctonas.

Fuentes: AOG (extractadas de García-Abad, 2009), resto (Datos y elaboración propios)

La impronta marcada por la cuadrícula más xenofítica de las nueve (C4) se extrapola al conjunto 9C: más de la mitad de las plantas exóticas son fanerófitos $(56,5 \%$ y $52,5 \%$, respectivamente), seguidos por los teróritos $(28,3 \%$ y $29,5 \%$, Idem) y hemicriptófitos (12\% y $12,3 \%$, Idem), siendo el resto de biótipos muy poco significativos. El alejamiento de los dos primeros biótipos de este ránking respecto al típico de AOG debe vincularse, sin más, a la particular implantación de cultivo/ornamentación desarrollada de manera singular en el entorno del núcleo de Miralrío.

Según el espectro corológico (Tabla 7), el centro de origen de las plantas alóctonas referenciadas en AOG está bastante repartido, sin que sea especialmente dominante ninguno de ellos. Está liderado por la agrupación de elementos tropicales estrictos (Cucurbita, Physalis, Setaria, entre otros géneros, suponen el 15,2\%), destacando sobre todo las plantas que se han naturalizado en ambientes ruderal-arvenses. En 9C este grupo tiene una muy baja representación, pues representa sólo el 8,2\% (Amaranthus hybridus, Conyza bonariensis, Echinochloa crus-galli y Setaria viridis se han encontrado muy pocas veces y como malas hierbas en ambientes algo mésicos). 
Tabla 7

NÚMERO DE PLANTAS ALÓCTONAS POR TIPOS DE DISTRIBUCIÓN GEOGRÁFICA (CON HÍBRIDOS)

\begin{tabular}{|c|c|c|c|c|c|c|c|c|c|c|c|}
\hline DISTRIBUCIÓN GEOGRÁFICA & AOG & $9 \mathrm{C}$ & C4 & $\mathbf{C 2}$ & C7 & C5 & C8 & C6 & C3 & Cl & C9 \\
\hline Estenomediterránea Oriental & 7 & 3 & 2 & 1 & 1 & 3 & 2 & 1 & 2 & 1 & 1 \\
\hline Estenomediterránea Occidental y SW & 3 & 3 & 3 & 1 & 1 & & 1 & 1 & & & \\
\hline Estenomediterránea & 5 & 2 & 2 & 1 & 1 & & 1 & 1 & & 1 & 1 \\
\hline Eurimediterránea & 11 & 9 & 7 & 1 & 1 & 1 & 2 & 2 & & 1 & 1 \\
\hline Europea & 7 & 3 & 2 & 2 & & 2 & & & 1 & & \\
\hline Eurosiberiana y/o Boreal (y Euni-) & 7 & 3 & 3 & 1 & 2 & 1 & 2 & 1 & & 1 & \\
\hline Irano-Turaniana/Sahariana (y Euri-) & 11 & 5 & 4 & 3 & 4 & 3 & 2 & 2 & 3 & 2 & 1 \\
\hline Europea/Eurieuropea/Perieuropea & 51 & 28 & 23 & 10 & 10 & 10 & 10 & 8 & 6 & 6 & 4 \\
\hline Euroasiática (y Euri-) & 11 & 7 & 5 & 3 & 2 & 1 & 1 & 2 & 1 & 1 & 1 \\
\hline Centroasiática & 6 & 1 & 1 & & & 1 & 1 & & 1 & & \\
\hline Asiática (no chinojaponesa) & 9 & 5 & 5 & 3 & 1 & 1 & 2 & 3 & 2 & 2 & 1 \\
\hline Africana y Afro-Asiática & 4 & & & & & & & & & & \\
\hline Holoártica & 1 & & & & & & & & & & \\
\hline Ampliamente Supraeuropea & 31 & 13 & 11 & 6 & 3 & 3 & 4 & 5 & 4 & 3 & 2 \\
\hline Chinojaponesa & 7 & 3 & 3 & 1 & 2 & 1 & 1 & & & & \\
\hline Norteamericana & 14 & 6 & 4 & 4 & 4 & 4 & 3 & 3 & 3 & 3 & \\
\hline Paleotropical & 6 & 2 & 1 & 1 & & 1 & & & 1 & & \\
\hline Neotropical & 15 & 3 & 2 & & 1 & & & & & & \\
\hline Sudamericana & 3 & 2 & 1 & 1 & 1 & & 1 & & 1 & & \\
\hline Americana (ambos subcontinentes) & 3 & 1 & & & & 1 & & & & & \\
\hline Australiana y Capense & 1 & & & & & & & & & & \\
\hline Ampliamente Extraeuropea & 49 & 17 & 11 & 7 & 8 & 7 & 5 & 3 & 5 & 3 & \\
\hline Desconocida o Incierta & 7 & 3 & 1 & & 1 & 1 & & 1 & & & \\
\hline
\end{tabular}

NOTA: Las cuadrículas de $1 \times 1 \mathrm{~km}$ aparecen, de derecha a izquierda, en orden descendente al número de alóctonas. Fuentes: AOG (extractadas de García-Abad, 2009), resto (Datos y elaboración propios)

En el modelo de AOG siguen los elementos estenomediterráneos (10,9\%; siendo 13,1\% en 9C) entre los que destacan por su gran frecuencia Medicago sativa, Olea europaea y Ficus carica ${ }^{6}$. Junto con las plantas eurimediterráneas (Vitis vinifera, Rhus coriaria, Cercis siliquastrum, Pinus spp., etc), constituirían un grupo mediterráneo amplio que casi supondría en AOG el $20 \%$ de todos los xenófitos (28\% en 9C). En 9C el elemento más recurrente es la violeta común (Viola odorata), que cultivada con fines ornamentales probablemente en el enclave hortelano de Miralrío parece haberse propagado a otros rincones húmedos, umbrosos o resguardados del entorno. Algo parecido ha debido ocurrir con Sorbus domestica, con fines alimenticios y Rhus coriaria, con fines tintóreos.

Importante en AOG es el grupo de plantas perieuropeas de los ámbitos áridos y muy áridos del Sur (Sáhara) y del SE (arco irano-turaniano), con un 8\%: centaureas arvenses, cereales agrícolas, Punica granatum y Cydonia oblonga, entre otros. En 9C (8,2\%), es generalizada la presencia de los arqueófitos Veronica polita y Centaurea cyanus, propias de ambientes agrícolas y removidos, además de Prunus dulcis cultivado. Destaca también en AOG las plantas de origen americano no estrictamente tropicales (14\% de las alóctonas).

6 La higuera aparece tanto cultivada, asilvestrada de cultivo como naturalizada en paredones de los escarpes calizos. 
De este origen son, precisamente los bledos y otros congéneres del género Amaranthus, así como los abrojos del género Xanthium, algunos de cuyos elementos son habituales en los cultivos y rastrojos de $9 \mathrm{C}$.

Tanto en AOG como en 9C, el grupo amplio euroasiático se encuentra en torno al 30\% de la flora alóctona (rosáceas frutícolas, arces, etc). Pero se trata de una agrupación especialmente variada en la que existen importantes y muy diferentes matices geográficos. Sobresale al respecto el centro de origen chinojaponés $(5,1 \%)$, de donde proviene Ailanthus altissima, árbol muy habitual en las cunetas de las carreteras, donde se asilvestra con muchísima facilidad. Otros elementos son ornamentales (Ligustrum lucidum, Lonicera japonica, etc). Elementos sobresalientes de otros centros euroasiáticos serían, por citar algún ejemplo: Juglans regia y Populus nigra (arqueófitos euroasiáticos), Syringa vulgaris y Pyrus communis (europeos) o Pinus sylvestris (eurosiberiano) que, siendo autóctono en la Península Ibérica, no lo es en AOG en el Holoceno reciente. De este gran grupo, en 9C es habitual la presencia de Asperugo procumbens, elemento especialmente nitrófilo, Veronica persica y Populus nigra, como naturalizadas; y Sophora japonica y Ulmus pumila (ambos en cunetas de carretera), Pyrus communis y Prunus domestica, como cultivados y, en su caso, asilvestrados.

Por último, queda analizar cuáles de estas plantas alóctonas tienen, además, carácter invasor en el sentido de Sanz et al. (2004); esto es, fitoelementos que al implantarse en tierras ajenas compromenten o pueden comprometer negativamente la estabilidad poblacional y ecológica de algunas especies autóctonas, llegando a desplazarlas de sus hábitat naturales y/o a mermar seriamente su existencia. Así pues, la Tabla 8 presenta el cuadro xenofítico desglosado según este criterio, con ratios comparativas. Y en la Figura 11 los datos se reducen a porcentajes.

Tabla 8

NÚMERO DE PLANTAS ALÓCTONAS INVASORAS Y NO INVASORAS, Y RATIOS

\begin{tabular}{|r|r|r|r|r|}
\hline Unidades & ALI (1) & \multicolumn{1}{|c|}{ ALNI (2) } & Ratio (3) & Ratio (4) \\
\hline C5 & 6 & 15 & 2,50 & 53,67 \\
C4 & 9 & 37 & 4,11 & 55,44 \\
C7 & 7 & 15 & 2,14 & 56,00 \\
C3 & 4 & 11 & 2,75 & 87,75 \\
C2 & 4 & 19 & 4,75 & 110,75 \\
C1 & 3 & 9 & 3,00 & 119,67 \\
C6 & 3 & 14 & 4,67 & 138,67 \\
C8 & 3 & 16 & 5,33 & 151,33 \\
C9 & 0 & 6 & no & no \\
9C & $\mathbf{1 1}$ & $\mathbf{5 0}$ & $\mathbf{4 , 5 5}$ & $\mathbf{6 4 , 3 6}$ \\
\hline AOG & $\mathbf{2 3}$ & $\mathbf{1 1 5}$ & $\mathbf{5 , 0 0}$ & $\mathbf{5 9 , 6 5}$ \\
\hline
\end{tabular}

(1) Plantas alóctonas invasoras, según adscripción de Sanz et al. (2004) para la Península Ibérica. (2) Plantas alóctonas no adscritas al grupo anterior. (3) Número de alóctonas no invasoras por cada alóctona invasora; Ratio=ALNI/ALI. (4) Número de plantas espontáneas no invasoras (ENI: 1372, en AOG; 708, en 9C; 359, en C1; 443, en C2; 351, en C3; 499, en C4; 322, en C5; 416, en C6; 392, en C7; 454, en C8; y 380, en C9) por cada alóctona invasora; Ratio=ENI/ALI. NOTA: Las cuadrículas de $1 \times 1 \mathrm{~km}$ aparecen, de arriba a abajo, en orden ascendente de la Ratio ENI/ALI. Fuente: AOG (extractadas de García-Abad, 2009), resto (Datos y elaboración propios).

En AOG, por cada planta alóctona invasora referenciada hasta ahora hay cinco que no lo son (o, expresado de otro modo, el 16,7\% de las plantas alóctonas son invasoras). Esta 
proporción es prácticamente la misma en 9C, con una ratio ligerísimamente menor. De este mismo orden de magnitud son las ratios de las cuatro cuadrículas que, precisamente, tienen mayor riqueza florística total $(\mathrm{C} 2, \mathrm{C} 4, \mathrm{C} 6$ y C8). Opuestamente, con excepción del caso especial de $\mathrm{C}$, las cuadrículas menos ricas tienen ratios menores y, por tanto, se alejan del modelo subregional. Si estas proporciones se calculan respecto a todas las plantas espontáneas, la proporción es que en AOG por cada planta invasora hay prácticamente sesenta plantas espontáneas no invasoras (esto es, el 1,7\% de las plantas espontáneas son invasoras). De esta manera, la ratio de $9 \mathrm{C}$ también resulta bastante similar respecto a la de AOG, aunque en este caso un poco mayor. Dicho de otro modo, con una ligera menor artificialización respecto a la subregión, Miralrío presenta un ligerísimo mayor valor pernicioso de invasoras. De ello puede deducirse que, en la actualidad, esas plantas marcarían una tendencia de más rápida y prevalente implantación en el territorio. En todo caso, salvo estos matices, 9C tiene un comportamiento muy parecido al de AOG. Las invasoras en AOG se expanden fundamentalmente por el cultivo agrícola. Esto se pone claramente de manifiesto observando cómo son los bledos (Amaranthus spp.), conizas (Conyza spp.) y abrojos (Xanthium spp.), es decir arvenses de primera fila, las más habituales. De hecho, en 9C son tres los bledos que aparecen casi siempre en las cuadrículas, así como Xanthium spinosum. Con otra ecología, el ailanto (Ailanthus altissima), la falsa acacia (Robinia pseudoacacia) o la caña (Arundo donax), entre algunos otros pocos táxones, también son habituales en las cunetas de carreteras, bordes o riberas degradadas de La Alcarria Occidental de Guadalajara. Y en Miralrío, desde luego, tampoco faltan estas plantas.

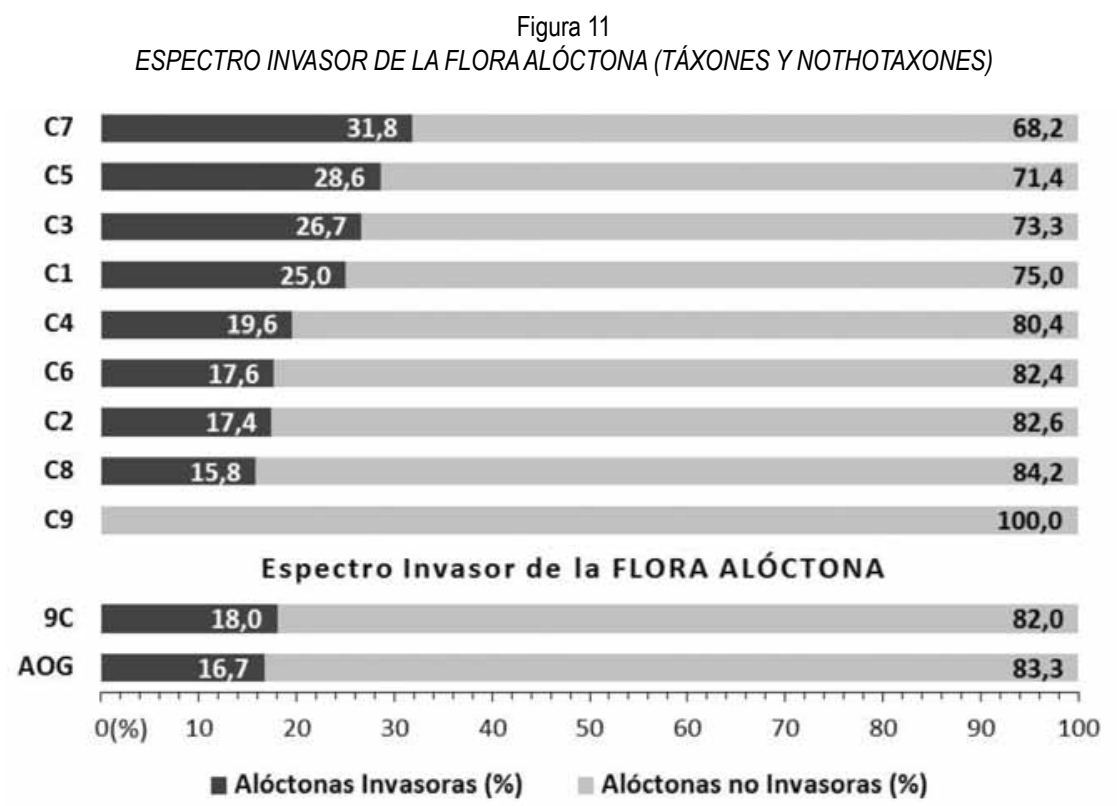

NOTAS: Las cuadrículas aparecen, de arriba a abajo, en orden descendente del porcentaje de plantas invasoras. Fuente: Las mismas de la Tabla 8. Elaboración propia. 


\section{DISCUSIÓN Y CONCLUSIONES}

En el conjunto de los trabajos efectuados sobre Miralrío (García-Abad y Panareda, 2012 y el presente) y en el contexto de estudios sobre Geografía de las Plantas en la región de La Alcarria Occidental y Mesa de Ocaña (García-Abad, 2009, 2011), se han vertido ideas y planteamientos teóricos enfocados a afrontar nuevas vías de investigación en Fitogeografía. Ha sido habitual que los estudios realizados por geógrafos hayan puesto más énfasis en tratar la vegetación en tanto que entidad fuertemente integradora e indicadora de las condiciones del medio. Normalmente, han incorporado bastantes referencias florísticas, aunque muy pocas veces con análisis exclusivos sobre la flora. Por ello, en nuestro caso, se ha propuesto una metodología de análisis florístico que sirva de referencia en futuros trabajos y que, sin perder la perspectiva geográfico-paisajística, tienda además puentes con otros tipos de estudios biogeográficos (botánicos, ecológicos y fitosociológicos). Esta propuesta se inscribe, además, en la línea de efectuar estudios de base y de reparar en el beneficio de cuidar la calidad de los datos. El análisis florístico ha empleado tratamientos habituales en Biogeografía, pero con la novedad de que: 1) se estudian unidades geográficas de base continuas, regulares y de muy poca extensión, para conocer una realidad más detallada; y 2) los valores obtenidos se contextualizan de manera anidada con los de la flora de las unidades naturales superiores a las que pertenecen. Mediante esta comparación anidada, se logran dos cuestiones: 1) que las cifras absolutas y porcentajes obtenidos pasen de tener el siempre importante valor descriptivo de aportar nuevos conocimientos, a detectar pautas también con valor predictivo; y 2) la prospección florística detallada, directa y actual permite revisiones y actualizaciones periódicas que propician el contraste permanente y mejora de las bases de datos.

Las cifras obtenidas en Miralrío sirven para evidenciar pautas biogeográficas cualitativas casi siempre ya conocidas, pero sobre todo para constatar valores y rangos bastante realistas y, por ello, útiles. En todo caso, debe advertirse que un catálogo florístico como el efectuado no puede considerarse nunca definitivo por la variabiliad inherente de los factores que intervienen en la germinación, desarrollo de las plantas, dinámica y evolución del tapiz vegetal.

En relación con la fragmentación y artificialización del paisaje que hacen quebrar los espectros florísticos naturales, una de las primeras pautas a considerar es la propia de la estructura agraria. En nuestro caso, Miralrío cumple el modelo que preside de manera generalizada la provincia de Guadalajara en cuanto a la propiedad rústica: minifundio acentuado e importancia del proceso de concentración parcelaria (Pillet, 2011). Este «manto» jurídico se ha superpuesto sobre el paisaje natural, ejes directrices ambos de los aprovechamientos, alcanzándose con el tiempo una concordancia integradora en unidades biofísicas que han soportado fases de mayor intensidad de uso y otras actuales mixtas de intensidad y abandono. Un buen ejemplo es la presencia del amplio bosque quercíneo de «La Alcarruela» y «Vallezuelo de Valdecastejón» (C6, C8 y C9), que responde a una regeneración espontánea tras periodos en que los miralrienses aprovecharon intensamente no sólo sus recursos forestales, sino que roturaron parte del mismo para ponerlo en cultivo. Posteriormente, abandonados esos aprovechamientos en las últimas décadas, además de lo poco que se mantuvo, la dinámica vegetal permitió recuperar un espacio que hoy posee una reconocida calidad florística dentro del contexto comarcal y subregional (García-Abad y Panareda, 2012). Y en esta dinámica, la actividad cinegética de carácter consuntivo-recreativa llevada a cabo durante el S. XX ha favorecido y sigue favoreciendo la conservación de lo regenerado según varios de los procesos y funciones expuestos por Rengifo 
(2010). Por otro lado, los encajados y guarecidos Vallezuelos de Cáritas y Valmuriel (C4 y $\mathrm{C} 2$ ), con los recursos hídricos generados por los exutorios acuíferos, dieron cabida a enclaves hortelanos de relativa importancia que, hoy en día, al estar abandonados o subtutilizados, dan lugar a una explosión de especies espinosas y de orla preforestal que protegen plantas no sólo de significado cultural, sino también de cierta relevancia naturalística. En las cercanías del pueblo (C4), sobre el escarpe de páramo, esas huertas, fuentes y abrevaderos constituían ese primer cinturón de explotación intensiva que produce rupturas y gradientes ambientales. Y, obviamente, la fitodiversidad crece, se «humaniza» y se propaga alrededor.

Los espectros y modelos fitoecológicos y biotípicos de la subregión de AOG aquí presentados son casi iguales o bastante similares a los de la región de La Alcarria Occidental y Mesa de Ocaña a la que pertenece (García-Abad, 2011). Podemos adelantar que ocurre también lo mismo con el modelo biogeográfico.

Las alteraciones del paisaje vegetal se manifiestan en dos desajustes espaciales básicos: a) cuanto más reducida es la extensión de unidades regulares que presenten de cierta a bastante fragmentación del paisaje, el componente ruderal-arvense de la flora se hace proporcionalmente mayor; y b) en los espacios de $1 \mathrm{~km}^{2}$ se alcanza una descomposición general de los grupos fitoecológicos; salvo alguna excepción cuando se mantienen buena parte de los elementos típicos del paisaje alcarreño. Y esa descomposición ocurre incluso dentro del grupo antropogénico ruderal-arvense. Sin embargo, en el espacio de $9 \mathrm{~km}^{2}$, los modelos espectrales comienzan a ser bastante similares a los de la subregión. Puede afirmarse, por tanto, que la estructura paisajística natural y cultural de AOG ya presenta pautas repetitivas en ese nivel de extensión superficial. Y es que la concentración de táxones de los principales grupos fitoecológicos es muy notable en un espacio regular de $9 \mathrm{~km}^{2}$, correlativamente con la correspondiente concentración de la mayor parte de los ambientes que caracterizan el paisaje en este sector alcarreño. Los datos y reflexiones que apoyan las afirmaciones precedentes serían que, por un lado, a) en el cómputo global, sólo un $20 \%$ de las plantas se encuentra en todos los recintos espaciales de $1 \mathrm{~km}^{2}$; esto es, un valor extraordinariamente reducido, si se tiene en cuenta que: b) las condiciones naturales anteriores a la artificialización antrópica del territorio miralriense serían poco heterogéneas; y c) los hitos de diversificación ambiental por ella generados han permitido, pese a todo, mantener en el conjunto 9C un $52,7 \%$ de toda la flora de AOG.

En el espectro biotípico, inicialmente destaca un matiz diferenciador entre la subregión y la región: el porcentaje de hemicriptófitos en AOG es casi un 2\% mayor que en La Alcarria Occidental y Mesa de Ocaña (32,9\%), debido a su carácter más montano (García-Abad, 2011). Como contrapartida, la región tiene un mayor porcentaje de terófitos $(38,5 \%)$ que la subregión, debido a su vez a un mayor rigor árido del periodo estival. Este matiz se convierte en ruptura del modelo, cuando se comparan los datos de la subregión con los de toda la Provincia de Guadalajara (Sancho y Reinoso, 2011,p. 43), donde los hemicriptófitos lideran el espectro $(40,6 \%)$ y los terófitos experimentan un merma destacada $(30,2 \%)$. La mayor diversidad geográfica de la provincia repercute también en el espectro biogeográfico: AOG tiene un mayor porcentaje de plantas mediterráneas amplias (61\%, endemismos incluidos) que la provincia $(55,6 \%)$, aunque sea menor el de endemismos; a cambio de reducir el peso de elementos (euri-) eurosiberianoboreales $(6,7 \%$ subregional, frente al $10,3 \%$ provincial).

Siguiendo con los biótipos, AOG cumple con la pauta general de la región mediterránea de tener una especial riqueza de especies anuales como resultado de la larga duración y constante 
evolución en ella de las actividades humanas (Blondel et al., 2010). Efectivamente, desde la inicial consideración como espacio periférico industrial emergente (Méndez y Rodríguez, 1998) al definitivo desarrollo socio-demográfico, urbano, comercial e industrial experimentado por el entorno de la capital guadalajareña y tramo provincial del Corredor del Henares (Pozo y Rodríguez, 2006; Río, Del y Rodríguez, 2009) han dotado a la subregión de elementos del paisaje muy artificializados que han favorecido una implantación destacada de terófitos. El entorno de Miralrío está algo menos antropizado que el promedio de AOG, pues la artificialización actual se debe casi exclusivamente a la propia del sector primario.

En cuanto a la procedencia de las plantas, la coincidencia de $9 \mathrm{C}$ es general con el modelo de AOG, con el matiz de que las alteraciones antrópicas amplifican los elementos eurimediterráneos frente a los endémico-estenomediterráneos. Pero, en los recintos más pequeños la artificialización ha operado detrayendo elementos extra/supramediterráneos. Los resultados muestran que el cuadrado 9C es plenamente representativo del espectro invasor propio de AOG a la que pertenece. Pero, se observa que cuando en los pequeños recintos espaciales la riqueza florística disminuye por alteraciones antrópicas, las plantas invasoras adquieren mayor proporción relativa.

Como consideraciones finales, se quiere remarcar que la composición florística detallada permite un conocimiento más fidedigno de los paisajes agrarios. En este sentido, gracias a análisis florísticos locales, se amplían datos sobre la incidencia de rotaciones de cultivos, pastoreo, rastrojos, setos, ribazos, márgenes, lindes, arbolados no productivos, riberas, islas de vegetación espontánea, manejos vegetativos, malezas, incendios, etcétera. Proliferan células del paisaje en donde la influencia humana secular ha transformado el paisaje sobreimponiéndose por encima de los factores naturales. Pero, además, en estos ambientes se introducen especies alóctonas, que encuentran un ambiente favorable en los espacios abiertos y nutrientes extraordinarios procedentes del ganado y vertido. La presencia de plantas alóctonas es un tema de notable interés biogeográfico pues supone un porcentaje nada desdeñable de la flora actual, pero no basta sólo con detectar su presencia. Futuros estudios deberán precisar en qué ambientes penetran, dónde se mantienen y dónde entran en clara competencia con la flora autóctona. Por otra parte, una especie no siempre se comporta como invasora de la misma manera en todos los territorios ni en todos los ambientes.

En suma, inicialmente, cuanto mayor sea el mosaico de ambientes, habrá más especies; pero el aumento se irá ralentizando según crezca el espacio considerado, porque las pautas generadas en espacios reducidos comenzarán a hacerse repetitivas. Por esto, interesa contrastar la estructura florística de espacios inferiores con los superiores en los que se incluye, pues en definitiva el entramado geográfico continuo se expresará en una suerte de compendio florístico cuyas expresiones sintéticas serán la fitodiversidad y la variación espacial de la misma. Y los estudios sobre Miralrío han pretendido poner las bases metodológicas para afrontar este tipo de análisis.

\section{REFERENCIAS}

BLONDEL, J., ARONSON, J., BODIOU, J.-Y. y BOEUF, G. (2010): The Mediterranean Region. Biological diversity in space and time. New York. Oxford University Press. Second Edition. BOLÒS, O. De y VIGO, J. (1984-2001): Flora dels Països Catalans. Barcelona. Barcino. 4 Vols. CASTROVIEJO, S. -Coord. Gral.- (1986-2008): Flora iberica. Plantas vasculares de la Península Ibérica e Islas Baleares. Madrid. Real Jardín Botánico. 13 Vols. 
COSTA, M. (1997): Biogeografía. En Izco, J. et al.: Botánica. Madrid. McGraw- Hill, 638-742. GARCÍA-ABAD, J.J. (2009): «Geografía de las plantas en La Alcarria Occidental y Mesa de Ocaña (I). Análisis florístico en cinco localidades representativas». Anales de Geografía de la Universidad Complutense, 29 (2), 127-153.

GARCÍA-ABAD, J.J. (2011): «Geografía de las plantas en La Alcarria Occidental y Mesa de Ocaña (II). Análisis fitoecológico y biotípico de la flora autóctona en cinco localidades representativas». Anales de Geografía de la Universidad Complutense, 31 (2), 103-124.

GARCÍA-ABAD, J.J. y PANAREDA, J.M. (2012): «Fitodiversidad geográfica de Miralrío comparada con la flora de La Alcarria Occidental de Guadalajara. Análisis taxonómico y de riqueza». Boletín de la A.G.E., 59, 245-274.

MATEO, G. y CRESPO, M.B. (2002): Reflexiones sobre las afinidades biogeográficas de la flora de la Cordillera Ibérica. Flora Montiberica, 21, 6-17.

MEAZA, G. -ed.- (2000): Metodología y práctica de la Biogeografía. Barcelona, Editorial del Serbal.

MÉNDEZ, R. y RODRÍGUEZ, J. (1998): «Procesos de industrialización periférica y espacios emergentes en Castilla-La Mancha». Anales de Geografía de la Universidad Complutense, 18 (1), 177-204.

PILLET, F. (2011): «La evolución de la propiedad y la riqueza catastral de Castilla-La Mancha y su relación con España». Anales de Geografía de la Universidad Complutense, 31 (1), 147-169.

POZO, E. y RODRÍGUEZ, J. (2006): «Transformaciones sociodemográficas recientes en las comarcas castellano manchegas limítrofes con la Comunidad de Madrid». Anales de Geografía de la Universidad Complutense, 26, 249-281.

RENGIFO, J.I. (2010): «Caza y turismo cinegético como instrumentos para la conservación de la naturaleza». Anales de Geografía de la Universidad Complutense, 30 (2), 163-186.

RÍO, I. Del, y RODRÍGUEZ, J. (2009): «Áreas metropolitanas en transformación. Presente y futuro del Corredor del Henares en el área funcional madrileña». Anales de Geografía de la Universidad Complutense, 29 (1), 139-165.

RIVAS-MARTÍNEZ, S., DÍAZ, T.E., FERNÁNDEZ-GONZÁLEZ, F., IZCO, J., LOIDI, J., LOUSÂ, M. Y PENAS, A. (2002): Vascular plant communities of Spain and Portugal. Addenda to the syntaxonomical checklist of 2001. Itinera Geobotanica, 15: 5-922.

RIVAS-MARTÍNEZ, S. y Cols. (2007): Mapa de series, geoseries y geopermaseries de vegetación de España (Memoria del mapa de vegetación potencial de España). Parte I. Itinera Geobotanica, 17, 5-436.

SANCHO, J. y REINOSO, D. (2011): Atlas de los paisajes de la Provincia de Gudalajara. Alcalá de Henares, Caja Guadalajara.

SANZ, M.; DANA, E. y SOBRINO, E. (2004): Atlas de las plantas alóctonas invasoras de España. Madrid, Ministerio de Medio Ambiente.

Páginas WEB [Última consulta, 30 de septiembre de 2012]:

ANTHOS-Sistema de Información sobre las plantas de España. www.anthos.es ATLAS DE LA FLORA DE ARAGÓN. http://proyectos.ipe.csic.es/floragon/index.php FLORA IBERICA-Plantas vasculares de la Penísula Ibérica e Islas Baleares. http://www. floraiberica.org. 